\title{
DESIGN OF COUPLED WALL STRUCTURES AS EVOLVING STRUCTURAL SYSTEMS
}

\author{
Abdelatee A. Eljadei ${ }^{1}$, Kent A. Harries ${ }^{2}$
}

\begin{abstract}
Coupled wall (CW) structures are outstanding lateral load resisting systems that not only reduce the deformation demands on the building, but also distribute inelastic deformation both vertically and in plan, between the coupling beams and the wall piers. When subjected to large seismic loads, coupling beams may deteriorate relatively quickly exhibiting both strength and stiffness degradation. This results in a rapid evolution in the performance of the CW system from behaving as a coupled wall system to behaving as a system of linked wall piers (LWP). This evolution of behavior is the focus of this work which considers a prototype 12-storey reinforced concrete coupled core wall (CCW) building. Five prototype variations, having the same wall pier pairs but degrading degrees of coupling were designed to study the effects of decayed coupling action. Elastic analyses using the equivalent lateral force (ELF) procedure and the continuous medium method (CMM) were used to establish initial proportions for the CCW prototype, and to determine the design forces and moments. Nonlinear static and dynamic analyses were conducted to investigate the CCW structural behavior, adequacy of the design, and the effect of the evolution of the structural form from a CCW system to a collection of LWPs. As expected, the structures having weaker coupling beams exhibited yield at lower lateral loads. The accompanying reduction in coupling stiffness, however, mitigated this effect although the wall pier demand clearly rose with reduced coupling. In every case, however, the walls embodied sufficient overstrength to permit the overall structure to perform well. An additional aspect of this work is that the wall piers in the CCW were significantly different in terms of their dynamic and geometric properties: the moments of inertia of the two wall piers of the CCW differed by almost an order of magnitude. The different wall pier capacities affected performance and require bi-directional pushover analyses but did not result in a significant reduction in capacity as may be initially intuited.
\end{abstract}

\footnotetext{
${ }^{1}$ Paul C. Rizzo Associates, Inc., Pittsburgh, Pennsylvania, USA (corresponding author).

Tel: (412) 825-2202, Fax: (412) 856-9749, E-mail: Abdelatee.Eljadei@rizzoassoc.com

${ }^{2}$ Department of Civil and Environmental Engineering, University of Pittsburgh, Pittsburgh, Pennsylvania, USA
} 


\section{INTRODUCTION}

Controlling the lateral displacement of a structure subject to seismic loads is a predominant issue in the design of mid- to high-rise buildings. This lateral displacement is considered to be a primary indicator of the degree of damage imparted to the structure and can additionally lead to unintended structure-structure interaction (i.e., pounding) if not controlled. Performance criteria in the performance-based design (PBD) approach are usually displacement based. Therefore, one goal in design is to provide adequate stiffness to ensure that this displacement is within acceptable limits.

Coupled walls (CW) are a common form of shear wall structure in residential and multistorey commercial buildings. A CW system resist lateral forces through a combination of flexural behavior of the wall piers and 'frame' action imparted by the coupling beams: an axial force couple is developed in the wall piers through the accumulation of shear in the coupling beams. The stiffness of the coupling beams governs the behavior of CW systems. The impact of the shear resistance of the beams is to make the CW system behave partly as a composite cantilever, bending about the centroidal axis of the wall group. The resulting stiffness of the coupled system is much greater than the summation of stiffnesses of the individual wall piers acting separately as uncoupled walls or in parallel as a collection of linked wall piers (LWP).

In a structural system, where lateral forces are resisted by a combination of systems, the more flexible component will exhibit lower ductility demand than the stiffer component of the structure. In the case of a coupled wall structure, the 'frame' action, that is: the axial forces in the walls resulting from the accumulated shear in the beams, is stiffer than the flexural response of the individual wall piers. As a result, the coupling beams exhibit greater ductility demands and damage than do the wall piers. As the damage progresses, it results in a structural system that may rapidly evolve from behaving as a coupled wall (CW) system to behaving as a collection of linked wall piers (LWP). Allowing the behavior of CW systems to evolve into that of a pair (or collection) of linked cantilever piers raises a number of concerns with regard to the dynamic behavior of such a system. Based on the expected evolution of performance, the linked wall pier system will be subject to large demands since the system is presumably behaving as a stiffer CW system at lower performance levels. In a sense, this evolving behavior may be represented as a progressive reduction in the degree of coupling (doc): 


$$
\text { doc }=\frac{C L_{W}}{C L_{W}+\sum R_{\text {wall }}}=\frac{C L_{W}}{O T M}
$$

Where: $\quad \mathrm{CL}_{\mathrm{w}}=$ Frame action of coupling beams

$\Sigma \mathrm{R}_{\text {wall }}=$ Moment resisted by wall piers

OTM = Overturning moment

If one considers the effective lateral stiffness of a CW system as a function of the doc, the effect of reducing the doc from an initial value (perhaps on the order of 55\%) to a very low value (say 10\%) results in an increase in structural flexibility (and therefore demand on the wall piers) on the order of $45 \%$ [1].

Traditional strength-based design (SBD) of CWs [2] often results in coupling beam demands in excess of capacities permitted by the concrete design code $[1,3]$. Inherently large redundancy factors associated with CWs, and directional effects [4] also result in increased shear demand on coupling beams. Studies have clearly shown that current strength-based analysis and design procedures typically result in excessive coupling beam shear and inadequate ductility [5,1]. It is clear from this discussion that the design of coupling beam elements is critical to the structural performance of a CW system. In this work, a performance-based design (PBD) methodology was used to design the CW system. PBD generally allows controlled non-linearity in specified structural members as long as certain structural and element performance criteria are satisfied. Also, it allows the designer to select how the structure will behave and provides the framework for selecting performance objectives for the structure.

A rational approach to CW design, founded on a PBD approach has been proposed [6]. The proposed PBD approach recognizes the preferred yielding mechanism of CWs [7] and takes advantage of the available ductility of the coupling beams. Figure 1a shows an idealized response of a CW designed using a PBD approach. In the case shown, the coupling beams were permitted to yield at a base shear $\left(\mathrm{V}_{\mathrm{B}}\right)$ lower than the code-prescribed design base shear $\left(\mathrm{V}_{\mathrm{C}}\right.$ at life safety (LS) performance objective) and the wall piers yielded at $\mathrm{V}_{\mathrm{W}} \approx \mathrm{V}_{\mathrm{C}}$. $\mathrm{V}_{\mathrm{D}}$ is the base shear corresponding to the CW attaining its code-prescribed drift limit (typically 2\%). Other performance spectra are possible such as allowing inelasticity in the wall piers at design base shear levels $\left(\mathrm{V}_{\mathrm{W}}<\mathrm{V}_{\mathrm{C}}\right)$.

In the present study, it is conceived that different behavior may be permitted at different performance levels. For example, a CW may be designed to behave as a CW system at the life 
safety (LS) performance level but as a collection of linked wall piers at the collapse prevention (CP) level (essentially, having exhausted the capacity of the beams) as shown in Figure 1b. In Figure 1, the fundamental structure considered was represented by its structural period: $\mathrm{T}_{\mathrm{CW}}$ for the CW system (Figure 1a) and $\mathrm{T}_{\mathrm{CW}}$ evolving into $\mathrm{T}_{\mathrm{LWP}}$ where only the wall piers provide lateral force resistance following designed-for exhaustion of the coupling beam capacity (Figure 1b).

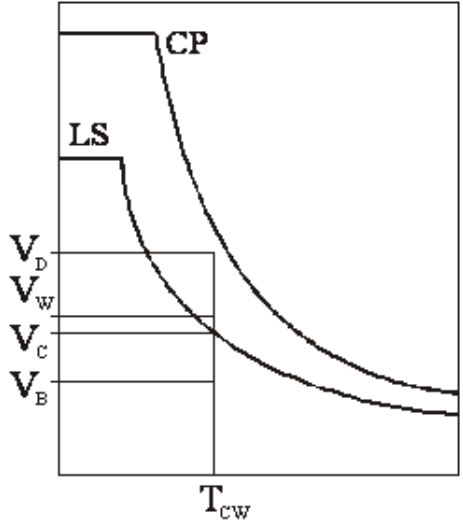

(a) schematic representation of PBD objective as described by Harries and McNeice (2006).

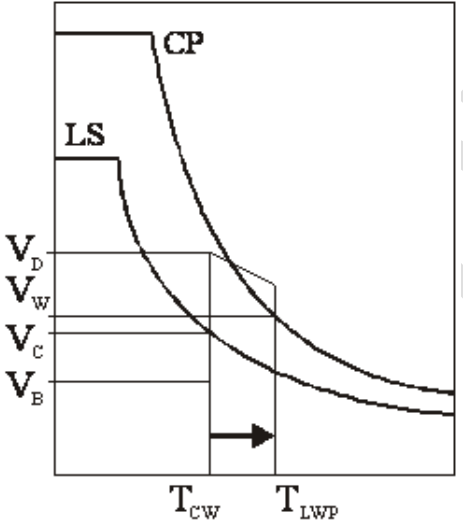

(b) schematic representation of PBD objective of CW treated as dual system.

Figure 1 Idealized spectral capacity behavior of a CW.

\section{OBJECTIVES OF PRESENT STUDY}

The objective of this study is to introduce and demonstrate a performance objective based on accepting and even leveraging the behavior of dual or evolving structural systems. In this approach, the performance domain was defined as the structural form of the lateral force resisting system (LFRS) itself: the LFRS of the structure was permitted (indeed, encouraged) to evolve from one form to another based on increasing demand during a seismic event. This rapid evolution may then be optimized to affect both rational performance criteria at various demand levels and economy in design. The example considered was the evolution of coupled core wall (CCW) systems to systems of linked wall piers (LWP) at increasing lateral load demands, shown schematically in Figure 2.

The concept is envisioned for a typical dual system as follows: The structure performs as a dual structure (in this case, as a coupled wall) at a particular (design) performance level. At a performance level having a greater demand, the capacity of one of the components of the dual system (coupling beams) is permitted to be exhausted as the structure essentially becomes a single LFRS structure (a collection of linked wall piers, in this case). Such an approach will 
result in a more rational performance for the structure and a more economical structural design particularly in cases where the components of the dual system have significantly disparate stiffness and thus proportional demands as is the case in CW.

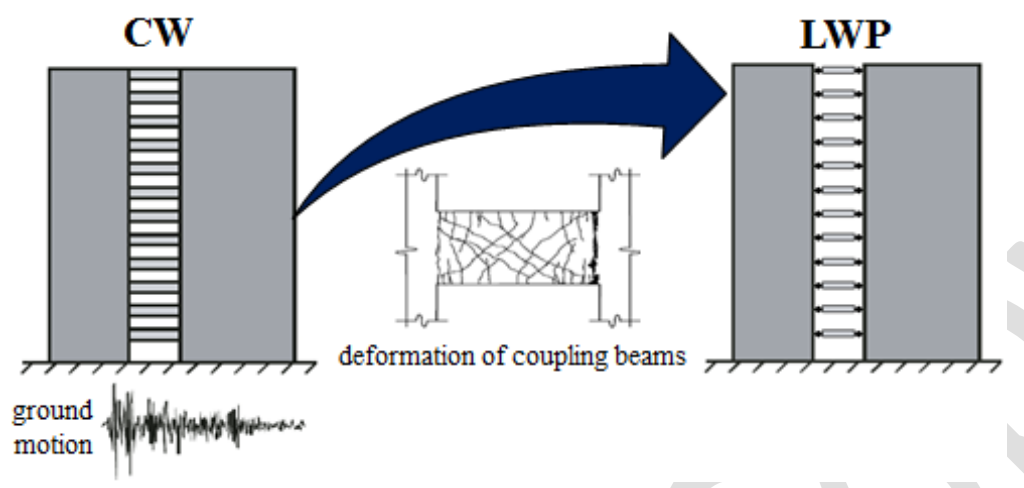

Figure 2 Evolution of CCW to LWP.

To illustrate this evolution, rather than attempting to define specific deterioration functions for the coupling beams, a series of analyses, each having subsequently reduced beam capacity is carried out. Each analysis is surrogate for a degree of beam deterioration and therefore a step in the evolution from CCW to LWP.

A second aspect of the present work was the focus on CW systems having wall piers with notably different mechanical and dynamic properties. Using the prototype described below, a performance-based approach to developing an initial viable design for a CCW structure was demonstrated; essentially validating the approach proposed by El-Tawil et al. [6] while extending it to a more complex structural geometry. Additionally, most previous analytical studies (first studied by Chitty and Wan 1948[8]; other early studies include: Beck 1962 [9] and Coull and Stafford-Smith 1967 [10] while more recent work includes El-Tawil et al. 2002[11]; Xuan et al. 2008[12]) and all previous experimental studies (e.g.: Santhakumar 1974[13]; Aristizabal-Ochoa and Sozen 1976[14]; Lybas and Sozen 1977[15]; Aristizabal-Ochoa et al. 1979[16]; Aktan and Bertero 1981[17]; Teshigawara 1998[18]) had focused on prismatic walls (i.e.: those having the same details over their height). McNeice is an exception having considered a 30 storey structure with four wall section geometries and five beam types. The present work develops a 'realistic' distribution of both wall and beam details vertically over the structure [19]. The application of non-traditional performance objectives based on the recommendations of Hull 
and Harries were also explored through the attempted extension of fixed point theory to the coupled wall design problem [20].

\section{TWELVE-STOREY PROTOTYPE STRUCTURES}

The following sections describe the initial design of the CCW prototype structure (intended to place the structure within the desired performance domain) and the iterations required to arrive at the final prototype design used for subsequent study. The initial design method and iterations illustrate the approach promulgated by El-Tawil et al. while extending this to CCW structures having markedly different pier geometries. The latter aspect is believed to be a unique aspect of this study [6].

The prototype structure considered is a twelve- storey residential structure located in Seattle WA. The structural design included only the design of the CCW lateral force resisting system (LFRS) of the building; no other structural components such as slabs, columns, beams, or foundation were designed. In the east-west direction, a coupled core wall (CCW) system is provided to resist $100 \%$ of the lateral loads applied to the structure. In the north-south direction, the LFRS consists of two components: the north-south oriented webs of the CCW and two outrigger cantilever shear walls located near the perimeter of the building. A plan of the entire building is shown in Figure 3a and an elevation view of the CCW is shown in Figure 3b. It is acknowledged that the building is an idealization, however its fundamental dimensions, mass and structure are consistent with simple residential and office structures located in the United States. Similar prototypes, designed by practicing engineers, have been used in previous studies [21, 22]. 


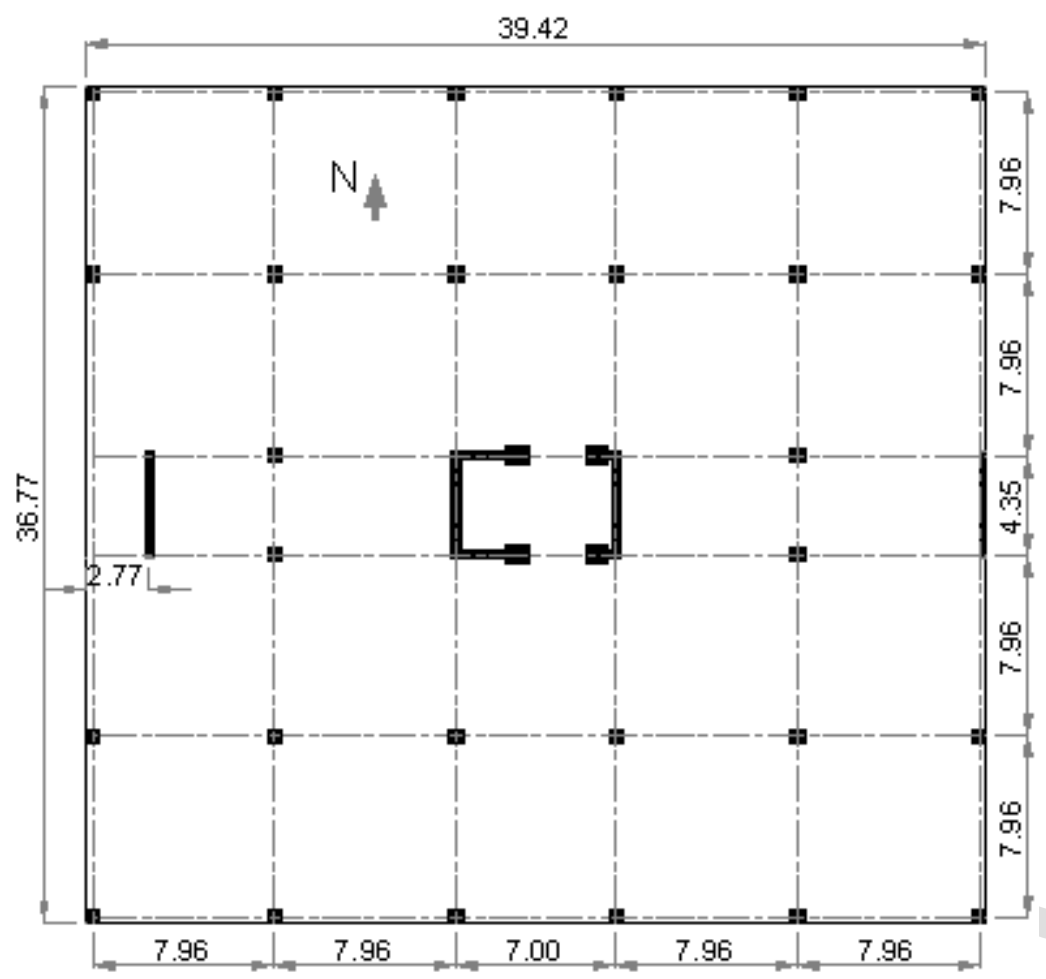

a) typical floor plan

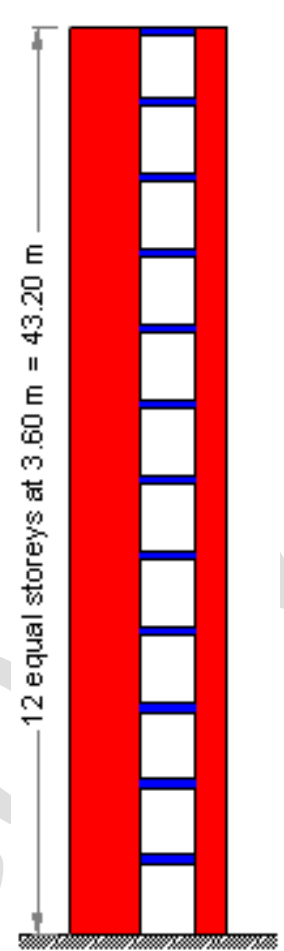

b) elevation

Figure 3 Prototype 12-storey building (dimensions are in meters).

\section{DEVELOPING THE INITIAL CCW GEOMETRY}

This study focused on CCWs having markedly different pier dimensions. The preferred behavior in this case is to have the two wall piers interacting to reduce lateral displacement, transmissibility and damage, and to provide sufficient energy dissipation capacity to the system [20]. The geometry of the CCW structure was therefore developed based on this desired behavior of the system.

The process of developing the wall geometry is iterative, and a parametric study was performed to develop a CCW system that meets the desired performance characteristics outlined below [23]. The calculation of the CCW dimensions was based on criteria that ensure a significant interaction between the wall piers while still maintaining a structural geometry that may be considered practical. The following initial criteria were selected to begin the iterative development of the east-west CCW geometry:

1. The natural frequency ratio, $\gamma$, between the wall piers is greater than 2.5 ; this criterion is intended to ensure significant interaction between piers [20]. It is noted that there is no 
predicted interaction (and therefore transmissibility reducing overall deflections) between wall piers having the same dynamic properties [20].

2. The roof drift at the design load level is less than $1 \%$; this criterion is typical of CCW structures and ensures that the structure has an appropriate overall stiffness.

3. The degree of coupling, doc, is in the range of 0.50; this value is recommended as a reasonable target value for an initial elastic design [6].

4. The seismic weight of each floor, $\mathrm{w}_{\mathrm{i}}=10000 \mathrm{kN}$; this is based on the structural geometry described above.

5. The total moment of inertia of the east-west CCW system is the sum of the contributing moments of inertia from the two wall piers and that resulting from the frame action of the coupling beams:

$$
\mathrm{I}_{\text {total }}=\mathrm{I}_{1}+\mathrm{I}_{2}+\mathrm{I}_{\text {frameaction }}
$$

In order to determine an initial estimate of the target moment of inertia, the CCW is considered as a cantilever beam subjected to an inverted triangular load. The free end elastic deflection (roof drift) for this condition is given as:

$$
\delta=\frac{11 W H^{3}}{60 E I_{\text {total }}}
$$

Where $\delta$ represents the roof deflection, $\mathrm{W}$ is the total lateral load, $\mathrm{H}$ is the CCW height, and $\mathrm{E}$ is the modulus of elasticity of concrete. For the given building height $(43.2 \mathrm{~m})$ and assumed roof drift limit (1\%), the target roof deflection was $432 \mathrm{~mm}$. From the ASCE 7-10 [4] equivalent lateral force (ELF) method analysis, the base shear, $\mathrm{V}$, for the prototype structure having a weight of $\mathrm{w}_{\mathrm{i}}=10000 \mathrm{kN}$ per floor was found to be $0.063 \mathrm{~W}=7522 \mathrm{kN}$, where $\mathrm{W}=\Sigma \mathrm{w}_{\mathrm{i}}$. The compressive strength of concrete was initially assumed to be $37 \mathrm{MPa}$ resulting in a modulus of elasticity of $28.5 \mathrm{GPa}$. In the resulting final design (described below) it was necessary to increase the concrete strength to $45 \mathrm{MPa}$. Based on these initial assumptions, from Equation 4, the target moment of inertia, $\mathrm{I}_{\text {total }}=9.03 \mathrm{~m}^{4}$. The sum of the moments of inertia for the two wall piers is related to the total moment of inertia through the degree of coupling:

$$
\sum \mathrm{I}_{\text {walls }}=(1-d o c) I_{\text {total }}
$$


Using a doc $=0.50$, the sum of the wall moments of inertia was found to be $4.51 \mathrm{~m}^{4}$. Frequency is a function of stiffness squared, therefore the ratio of wall pier moments of inertia may be found by equating to $\gamma^{2}$ :

$$
\frac{I_{2}}{I_{1}}=\gamma^{2}
$$

Through experience gained in this study, it was found that the initial estimate of $\gamma$ using this simplified approach must exceed the target value by about $30 \%$ in order for the target value to be achieved. Therefore, an initial value of $\gamma=3.2$ was assumed resulting in the wall piers' moments of inertia being estimated as $\mathrm{I}_{1}=0.40 \mathrm{~m}^{4}$ and $\mathrm{I}_{2}=4.11 \mathrm{~m}^{4}$ (Wall 1 was arbitrarily selected as being the more flexible wall). Having established the wall piers' moments of inertia, the initial dimensions can be estimated. Some geometric assumptions were applied in this case: the interior width of the system, $b_{w}=4.0 \mathrm{~m}$, the uniform wall thickness, $\mathrm{t}=0.35 \mathrm{~m}$, and the coupling beam length, $b=2.5 \mathrm{~m}$. With these values, the wall pier lengths, $h_{w 1}$ and $h_{w 2}$, were estimated.

To ensure that the selected wall piers have a frequency ratio greater than 2.5 , the eigenvector method [24] was used to calculate natural vibration frequencies of the 2 SDOF systems representing the cantilever wall piers. Beginning with the initially assumed frequency ratio $\gamma=3.2$, the calculated ratio based on the equivalent properties of the wall piers was $\gamma=2.58$ [23], which satisfies the criterion assumed for developing the CCW geometry.

\section{ELASTIC ANALYSIS OF INITIAL PROTOTYPE STRUCTURE}

The dead, live and seismic loads applied on the structure were determined according to the provisions of ASCE 7-10 [4]. The storey mass was assumed to be $10000 \mathrm{kN}$. The site class for the building location was assumed to be Site Class C. The design, 5\% damped spectral response acceleration parameters for the Seattle site for short $(0.2 \mathrm{~s})$ and 1 second periods are $\mathrm{S}_{\mathrm{DS}}=1.00 \mathrm{~g}$ and $\mathrm{S}_{\mathrm{D} 1}=0.433 \mathrm{~g}$, respectively. According to the building occupancy, and based on the spectral response parameters, the structure belongs to Seismic Design Category D (SDC D). Initial structural analysis was conducted using a two-step process. The Equivalent Lateral Force (ELF) Method prescribed by ASCE 7-10 [4] was implemented from which the fundamental period of vibration of the structure, $\mathrm{T}=1.15 \mathrm{sec}$ and the base shear, $\mathrm{V}=7522 \mathrm{kN}$ were determined. The base shear was then distributed linearly in an inverted triangular pattern along the height of the 
structure and the closed-form equations of the Continuous Medium Method (CMM, described by Stafford Smith and Coull [25] and Harries et al. [1, 21]) were used to determine the coupling beam and wall pier demands. The CCW structure was analyzed in only the east-west direction; torsional effects were eliminated by ensuring that the shear center of the LFRS system coincides with the center of mass of the structure. Following the design of the CCW in the east-west direction, the north-south cantilever wall behavior was verified as will be described subsequently.

In the Continuous Medium Method analysis, the coupling beams were assumed to have a rectangular section with dimensions of $0.50 \mathrm{~m}$ deep and $0.35 \mathrm{~m}$ wide and calculations were based on service level doc. Since the coupling beams are expected to deteriorate faster than the wall piers and the doc falls with increasing loads [5], different reduction factors were applied to the moments of inertia of the coupling beams $\left(\mathrm{I}_{\mathrm{b}}=0.70 \mathrm{I}_{\mathrm{bg}}\right)$ and wall piers $\left(\mathrm{I}_{\mathrm{w}}=0.95 \mathrm{I}_{\mathrm{wg}}\right)$ to account for concrete cracking at service load levels. The axial rigidity of the beams and walls were not reduced (i.e.: $A_{b}=A_{b g}$ and $A_{w}=A_{w g}$ ).

The CMM parameters $\alpha$ and $\mathrm{k}$ were calculated as $0.0886 \mathrm{~m}^{-1}$ and 1.043 , respectively. The product of these parameters with the overall height of the CCW, $k \alpha H=3.98$ is interpreted as a measure of the stiffness of the coupling beams, and is most sensitive to changes in either the stiffness or length of the coupling beam (which are, of course, related). This parameter was used to calculate the degree of coupling (doc), axial load distribution in the wall piers (N), shear flow in the continuum representing the coupling beams $(\mathrm{q})$ and the lateral deflection $\left(\mathrm{y}_{\mathrm{H}}\right)$ (doc: Harries et al. [1, 21]; N, q and ун: Stafford-Smith and Coull [25]). The lateral load, p, was determined by distributing the base shear, V, obtained from the ELF analysis in an inverted triangular pattern. The value of $\mathrm{p}$ at the top of the wall was calculated as: $\mathrm{p}=\mathrm{V} /(0.5 \times \mathrm{H})=7522 /(0.5 \times 43.20)=$ $348 \mathrm{kN} / \mathrm{m}$. A summary of the wall pier parameters and calculated values for the CMM analysis of the initial CCW design is given in Table 1.

The doc for the initial CCW structure was found to be 0.61. The axial forces in the wall piers $(\mathrm{N})$, the shear flow in the coupling beams $(\mathrm{q})$ and the lateral deflection (y) are continuous and integrated over the storey heights tributary to each storey. The base overturning moment was also calculated; the frame action component of this overturning resistance was determined by multiplying the axial force in the wall piers resulting from the accumulation of beam shear, $\mathrm{N}$, by the lever arm between the tension-compression couple, $\mathrm{L}_{\mathrm{w}}$. The remaining overturning moment 
is resisted by the individual wall piers in proportion to their flexural stiffness. The CMM analysis of the initial prototype design confirmed that the design fell within the desired performance parameters and established elastic design values for the coupling beams and wall piers from which the design process progressed as described in the following sections.

Table 1 Data used in CMM analysis of CCW

\begin{tabular}{|c|c|c|c|}
\hline \multicolumn{2}{|l|}{ gross section property } & $\begin{array}{c}\text { initial CCW } \\
\text { design }\end{array}$ & $\begin{array}{c}\text { final CCW design } \\
\text { with barbells }\end{array}$ \\
\hline Base shear & $\mathrm{V}_{\mathrm{c}}$ & \multicolumn{2}{|c|}{$7522 \mathrm{kN}$} \\
\hline Triangularly distributed lateral load at top of structure & $\mathrm{p}$ & \multicolumn{2}{|c|}{$348 \mathrm{kN} / \mathrm{m}$} \\
\hline Total height & $\mathrm{H}$ & \multicolumn{2}{|c|}{$43.20 \mathrm{~m}$} \\
\hline Coupling beam height & $\mathrm{h}_{\mathrm{b}}$ & \multicolumn{2}{|c|}{$0.50 \mathrm{~m}$} \\
\hline Coupling beam width & $\mathrm{W}_{\mathrm{b}}$ & \multicolumn{2}{|c|}{$0.35 \mathrm{~m}$} \\
\hline Length of coupling beam & $\mathrm{L}_{\mathrm{b}}$ & \multicolumn{2}{|c|}{$2.50 \mathrm{~m}$} \\
\hline Distance between wall centroids & $\mathrm{L}_{\mathrm{w}}$ & $5.82 \mathrm{~m}$ & $5.28 \mathrm{~m}$ \\
\hline Storey height & $\mathrm{h}$ & \multicolumn{2}{|c|}{$3.60 \mathrm{~m}$} \\
\hline Young's modulus & $\mathrm{E}$ & $28.5 \mathrm{GPa}$ & $31.75 \mathrm{GPa}$ \\
\hline Shear moduls of coupling beams & $\mathrm{G}$ & $11.87 \mathrm{GPa}$ & $13.23 \mathrm{GPa}$ \\
\hline Poisson’s ratio & v & \multicolumn{2}{|c|}{0.20} \\
\hline Cross-sectional correction coefficient for shear & $\lambda$ & \multicolumn{2}{|c|}{1.20} \\
\hline Moment of inertia of Wall 1 & $\mathrm{I}_{1}$ & $0.41 \mathrm{~m}^{4}$ & $0.73 \mathrm{~m}^{4}$ \\
\hline Moment of inertia of Wall 2 & $\mathrm{I}_{2}$ & $4.18 \mathrm{~m}^{4}$ & $6.66 \mathrm{~m}^{4}$ \\
\hline Cross sectional area of Wall 1 & $\mathrm{~A}_{1}$ & $2.45 \mathrm{~m}^{2}$ & $3.43 \mathrm{~m}^{2}$ \\
\hline Cross sectional area of Wall 2 & $\mathrm{~A}_{2}$ & $3.74 \mathrm{~m}^{2}$ & $4.72 \mathrm{~m}^{2}$ \\
\hline Cross sectional area of coupling beam & $\mathrm{A}_{\mathrm{b}}$ & $0.35 \mathrm{~m}^{2}$ & $0.35 \mathrm{~m}^{2}$ \\
\hline Gross moment of inertia of coupling beam & $\mathrm{I}_{\mathrm{b}}$ & $0.0051 \mathrm{~m}^{4}$ & $0.0051 \mathrm{~m}^{4}$ \\
\hline Effective moment of inertia of coupling beam & $\mathrm{I}_{\mathrm{C}}$ & $0.0047 \mathrm{~m}^{4}$ & $0.0047 \mathrm{~m}^{4}$ \\
\hline Parameter of the relative flexibility of coupling beams & $\alpha$ & $0.0886 \mathrm{~m}^{-1}$ & $0.623 \mathrm{~m}^{-1}$ \\
\hline Relative flexural to axial stiffness of wall piers & $\mathrm{k}$ & 1.043 & 1.062 \\
\hline Coefficient measures the stiffness of coupling beam & $\mathrm{k} \alpha \mathrm{H}$ & 3.981 & 2.900 \\
\hline Degree of coupling & doc & 0.611 & 0.505 \\
\hline
\end{tabular}

\section{DESIGN OF COUPLING BEAMS AND ITERATION OF WALL PIER DESIGN}

The desired behavior for the coupling beams in a CCW system is to yield essentially simultaneously at the code-prescribed base shear [6]. To achieve this objective, the coupling beams should optimally be designed to match the vertical distribution of shear demand, in this case determined using the CMM. Typically for a CCW, the most highly stressed coupling beams are located at approximately one third up the height of the structure. The critical coupling beams for the initial prototype twelve-storey building carry $1241 \mathrm{kN}$ and are located at the $6^{\text {th }}$ floor.

For the prototype structure, design of the coupling beams as conventional reinforced concrete coupling beams would result in impractical beams with an impractically large amount of reinforcing steel [3]. As a point of reference, if the coupling beams were designed to carry the 
maximum ACI 318-11-permitted shear stress of $0.83 \sqrt{f_{c}{ }^{\prime}}$ (which is generally not feasible), their dimensions would be on the order of $610 \mathrm{~mm}$. deep [2]. Diagonally reinforced coupling beams in this case are also ineffective due to the small angle of inclination resulting from the relatively long beams [3]. Thus, flexure-critical steel coupling beams were used for the prototype structure (Harries et al. [26, 27]; El-Tawil et al. [6]). Because the coupling beams are relatively long, they were designed using rolled W-sections in order to simplify the construction process.

In order to develop analytical models that accomplish the study objective of investigating the effect of beam deterioration and subsequent evolution from CCW to LWP, five different scenarios for the coupling beams were investigated. The beams were designed to resist $100 \%$, $90 \%, 80 \%, 70 \%$, and $60 \%$ of their shear demand calculated from the CMM analysis. Thus five prototype structures resulted - referred to by their percentage of the shear demand - each having the same wall details but different beam details. For reasons of uniformity and constructability, the rolled sections selected for the beams of each individual structure were selected from the same section group. W14 sections were used for the 100\% and 90\% structures, while W12 sections were used for the $80 \%, 70 \%$, and $60 \%$. For the $100 \%$ structure, the maximum shear demand in the coupling beams $\mathrm{V}_{\mathrm{u}}=1241 \mathrm{kN}$ leads to moment demand, $\mathrm{M}_{\mathrm{u}}=\mathrm{V}_{\mathrm{u}} \mathrm{b} / 2=1551 \mathrm{kN}$ $\mathrm{m}$. The resulting rolled section, a W14x176 (US designation), was used for the beams at the fourth, fifth and sixth storeys.

The W14x176 rolled section has a flange width of $0.40 \mathrm{~m}$ which was greater than the wall thickness, $0.35 \mathrm{~m}$. There are no suitable rolled sections having sufficiently thin flange widths to be embedded in the wall toes and it was not felt practical to design a built up section with a sufficiently narrow flange. Additionally, as the wall reinforcement was detailed it became apparent that planar walls cannot accommodate both the large amounts of reinforcement and the embedded steel section, regardless of its width. For these reasons, a 'barbell' was added to the wall toes throughout the height of the building. The barbells were sized based on the practical limitation of embedding the steel coupling beam section and providing sufficient vertical reinforcement in the boundary elements of the wall piers.

The addition of the barbells resulted in a significant change to the geometric properties of the wall piers necessitating a revised CMM analysis to update design loads. The revised values for the eventual final CCW design, including the barbells, are summarized in Table 1 . The gross section area increased $40 \%$ and $26 \%$ for walls 1 and 2, respectively. Similarly, the gross section 
moments of the inertia increased 78\% and 59\% for walls 1 and 2, respectively. These nonproportional changes resulted in a stiffer wall pier system, reduced doc $=0.50$ and different relative and overall dynamic properties. Design overturning moments (that for each wall pier, the couple, and the sum of these) from the CMM analyses of the final structure are shown in Figure 4. The bean shear demands are shown in the first column in Table 2. The beam and wall designs progressed using these revised values. The final coupling beam selections for all prototype structures are shown in Table 2.

Table 2 Final design of steel coupling beams for all prototype structures (U.S designations for rolled sections)

\begin{tabular}{|c|c|c|c|c|c|c|}
\hline \multirow{2}{*}{ Storey } & $\begin{array}{c}\text { Design Shear for } \\
100 \% \text { structure }\end{array}$ & \multicolumn{5}{|c|}{ Structure } \\
\cline { 2 - 7 } & $\mathrm{kN}$ & $100 \%$ & $90 \%$ & $80 \%$ & $70 \%$ & $60 \%$ \\
\hline 12 & 827 & $\mathrm{~W} 14 \times 120$ & $\mathrm{~W} 14 \times 109$ & $\mathrm{~W} 12 \times 120$ & $\mathrm{~W} 12 \times 96$ & $\mathrm{~W} 12 \times 87$ \\
\hline 11 & 850 & $\mathrm{~W} 14 \times 120$ & $\mathrm{~W} 14 \times 109$ & $\mathrm{~W} 12 \times 120$ & $\mathrm{~W} 12 \times 96$ & $\mathrm{~W} 12 \times 87$ \\
\hline 10 & 899 & $\mathrm{~W} 14 \times 132$ & $\mathrm{~W} 14 \times 120$ & $\mathrm{~W} 12 \times 120$ & $\mathrm{~W} 12 \times 106$ & $\mathrm{~W} 12 \times 96$ \\
\hline 9 & 961 & $\mathrm{~W} 14 \times 145$ & $\mathrm{~W} 14 \times 132$ & $\mathrm{~W} 12 \times 136$ & $\mathrm{~W} 12 \times 120$ & $\mathrm{~W} 12 \times 106$ \\
\hline 8 & 1019 & $\mathrm{~W} 14 \times 145$ & $\mathrm{~W} 14 \times 132$ & $\mathrm{~W} 12 \times 136$ & $\mathrm{~W} 12 \times 120$ & $\mathrm{~W} 12 \times 106$ \\
\hline 7 & 1063 & $\mathrm{~W} 14 \times 159$ & $\mathrm{~W} 14 \times 145$ & $\mathrm{~W} 12 \times 136$ & $\mathrm{~W} 12 \times 120$ & $\mathrm{~W} 12 \times 106$ \\
\hline 6 & 1085 & $\mathrm{~W} 14 \times 159$ & $\mathrm{~W} 14 \times 145$ & $\mathrm{~W} 12 \times 136$ & $\mathrm{~W} 12 \times 120$ & $\mathrm{~W} 12 \times 106$ \\
\hline 5 & 1068 & $\mathrm{~W} 14 \times 159$ & $\mathrm{~W} 14 \times 145$ & $\mathrm{~W} 12 \times 136$ & $\mathrm{~W} 12 \times 120$ & $\mathrm{~W} 12 \times 106$ \\
\hline 4 & 1005 & $\mathrm{~W} 14 \times 145$ & $\mathrm{~W} 14 \times 132$ & $\mathrm{~W} 12 \times 136$ & $\mathrm{~W} 12 \times 120$ & $\mathrm{~W} 12 \times 106$ \\
\hline 3 & 881 & $\mathrm{~W} 14 \times 132$ & $\mathrm{~W} 14 \times 120$ & $\mathrm{~W} 12 \times 120$ & $\mathrm{~W} 12 \times 106$ & $\mathrm{~W} 12 \times 96$ \\
\hline 2 & 685 & $\mathrm{~W} 14 \times 120$ & $\mathrm{~W} 14 \times 109$ & $\mathrm{~W} 12 \times 96$ & $\mathrm{~W} 12 \times 79$ & $\mathrm{~W} 12 \times 72$ \\
\hline 1 & 396 & $\mathrm{~W} 14 \times 61$ & $\mathrm{~W} 14 \times 61$ & $\mathrm{~W} 12 \times 58$ & $\mathrm{~W} 12 \times 50$ & $\mathrm{~W} 12 \times 45$ \\
\hline
\end{tabular}

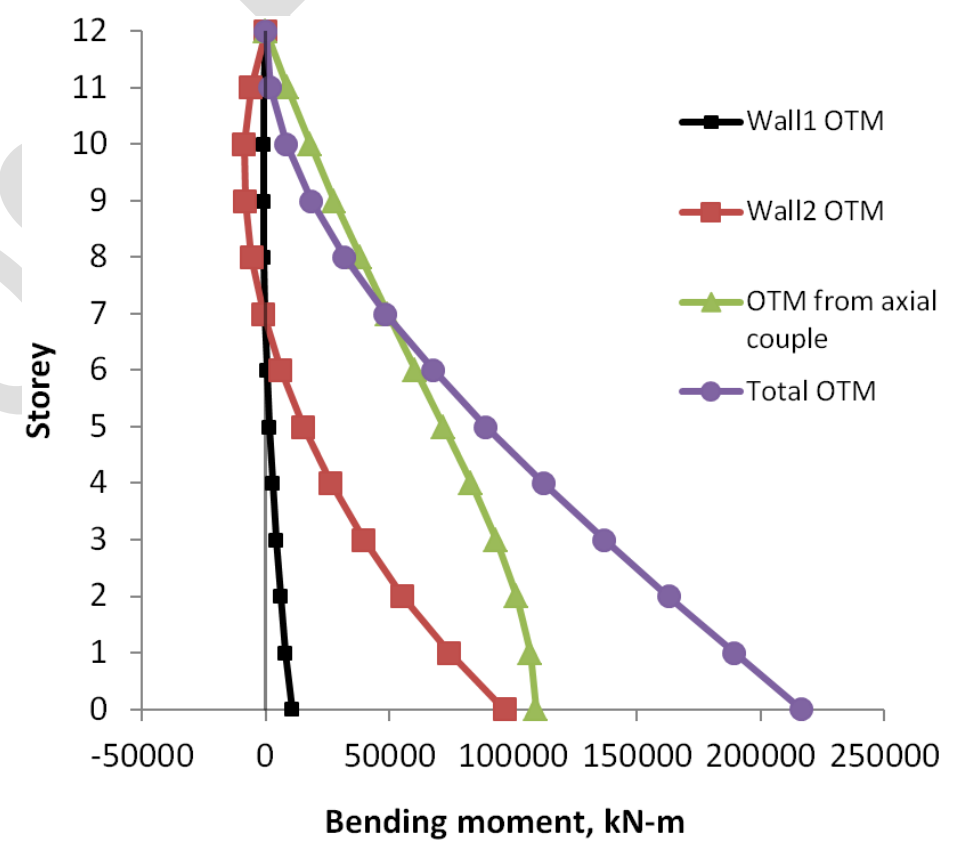

Figure 4 Overturning moments (OTM) for final CCW design. 


\section{DESIGN OF WALL PIERS}

The wall piers were designed for the demand generated in the $100 \%$ structure only; in this manner the structures having $60 \%$ to $90 \%$ beam capacity may be considered surrogate for the $100 \%$ structure having degraded beam capacity. Overstrength factors were taken as unity [6]. Each pier was divided into five sections along the height of the building: a) the expected plastic hinge region extending over storeys 1 and 2; b) storeys 3 and 4; c) storeys 5, 6 and 7; d) storeys 8-10; and e) storeys 11-12. Due to the large wall moment demands, it was necessary to increase the concrete strength from the initially assumed $37 \mathrm{MPa}$ to $45 \mathrm{MPa}$. Similarly, the yield strength of the shear and flexural reinforcing steel was selected to be $517 \mathrm{MPa}$ in order to mitigate reinforcing bar congestion in the design. The walls were first designed for their east-west moments. The provision of additional capacity from the north-south outrigger walls ensured that the east-west (coupled direction) capacity could control the design of the CCW and no additional steel was required to carry north-south moments. In the wall design, \#9 (29 mm) primaryreinforcing bars and \#4 (13 mm) shear, confinement and distributed reinforcing bars were used.

Figure 5a shows the reinforcement details for the base level (plastic hinge region) of the CCW. At the beam-wall connection regions, penetration of the confining cross ties through the beam web was avoided - this was felt to be a complex and unnecessary detail [28]. Two details the first immediately above and below the embedded beam section and the second in the web region of the embedded beam section are shown for wall 1 barbells in Figures $5 b$ and 5c. Reinforcing details naturally taper up the height of the structure and in the upper two storeys were controlled by ACI-prescribed minimum reinforcement requirements. In these storeys, the primary reinforcement was reduced to \#6 $(19 \mathrm{~mm})$ and \#7 $(22 \mathrm{~mm})$ bars. Details of all wall sections are provided in Eljadei (2012) [23]. 


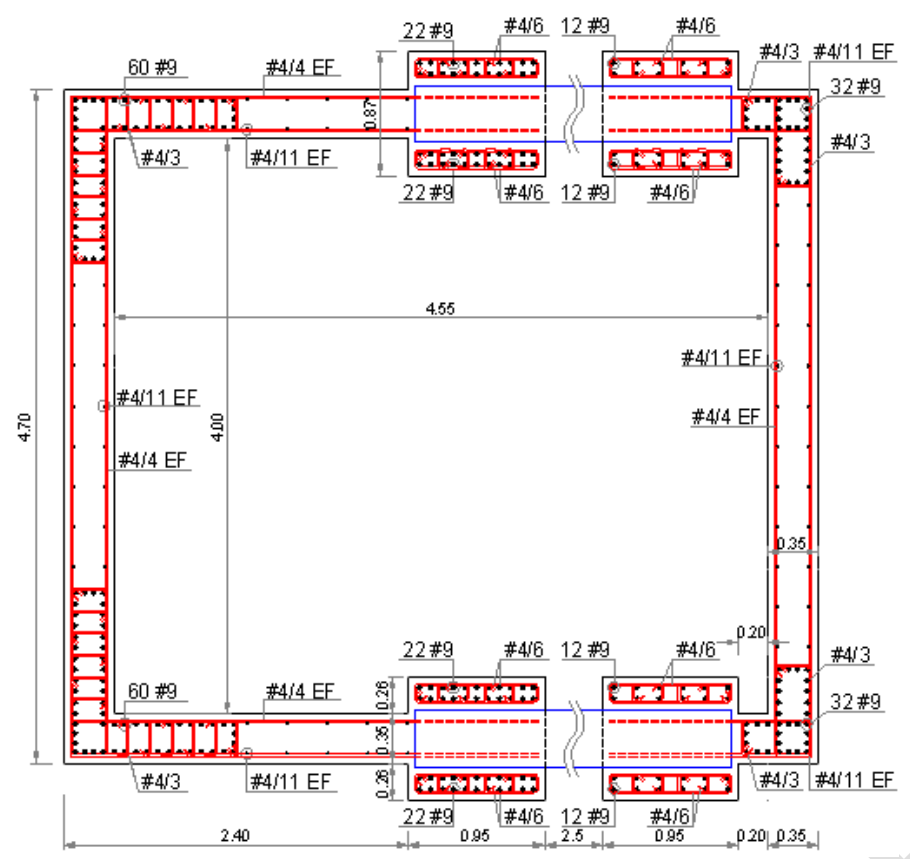

a) stories 1-2 (dimensions are in meters) Wall 2 is on left; Wall 1 on right.

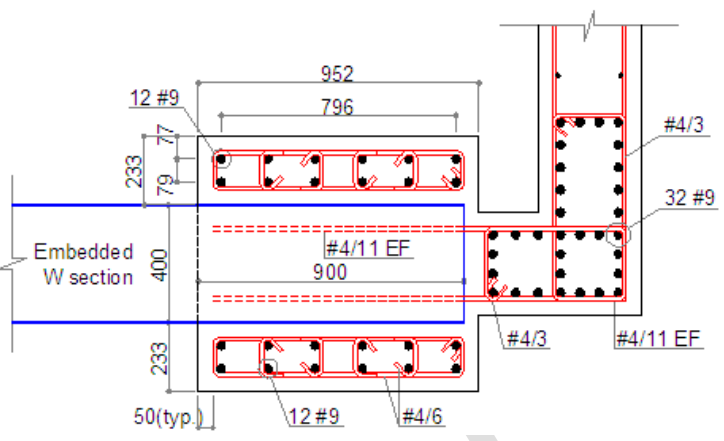

b) wall 1 barbell in the web region of the coupling beam (dimensions are in centimeters)

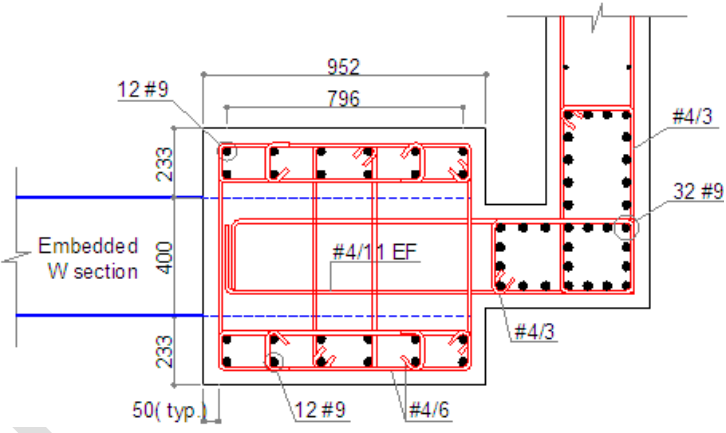

c) wall 1 barbell at level above/below the coupling beam (dimensions are in millimeters)

Figure 5 Reinforcing details near base of prototype structure (U.S designations for reinforcing steel).

\section{NON-LINEAR STATIC (PUSHOVER) ANALYSIS OF PROTOTYPE}

\section{STRUCTURES}

Once the structural design of the CCW elements was complete, the structure was modeled for conducting a nonlinear static analysis. The computer software RUAUMOKO was used to perform all nonlinear static and dynamic analyses [29]. In this study, the CCW system was modeled in two dimensions and the effect of torsion was eliminated by positioning the center of rigidity of the LFRS coincident with the center of mass of the building. RUAUMOKO permits an adaptive pushover procedure to be used in which the loading pattern is revised at each analysis step to reflect the deformation pattern of the structure [30]. This is an approximate method of addressing higher-mode effects that result from variation of inertial forces over the structure's height. Using RUAUMOKO, an initial load pattern was selected (in this study, the inverted triangular load of the ELF method) and the adaptive pushover refines this at each load step based on calculated displacement. 
Because the wall piers are C-shaped, their capacities in the east and west directions differ. Therefore two pushover analyses are required: one with the load acting in the west-to-east (WE) direction and the second with load acting east-to-west (EW). In the WE pushover, Wall 1 is the 'compression' wall (leeward wall in a wind analysis) and Wall 2 is the 'tension' wall (windward). In the EW direction, the wall forces were reversed.

In this study, the diagonal mass representation was used, where mass is lumped at each translational degree of freedom (DOF) and the contribution of the rotational DOF is obtained as the diagonal term of the appropriate consistent mass matrix for the member considered [29]. Because the CCW resists $100 \%$ of the lateral loads in the direction of analysis, $100 \%$ of the storey mass was applied at each storey level. The mass was divided between the wall piers based on their relative area although since lateral degrees of freedom were constrained, this was not strictly necessary. The model used the Equivalent Frame Method, and Giberson one-component beams to represent the steel coupling beams [29]. In the two-dimensional frame analysis, each beam element in the model represents the two coupling beams at a respective storey level; therefore the properties assigned to the element were twice those of a single coupling beam. The wall piers were modeled using a general quadratic beam-column model. The wall elements are located at the centroids of each C-shaped wall pier. Since the beam elements span the entire lever arm between the piers' centroids, they must be connected to wall elements by rigid links of lengths equal to the distances between the centroids and beam-wall interfaces. These links mimic the 'plane sections' response of the wall pier and result in the beams spanning their appropriate lengths. The lengths of the rigid links are $0.905 \mathrm{~m}$ and $1.871 \mathrm{~m}$ from walls 1 and 2, respectively.

In this study the expected hinge region at the base of the walls was assumed to extend through the second floor; greater stiffness reduction factors were therefore used for the first two storeys. Based on previous studies [22] and a synthesis of international code-prescribed values [5], the effective flexural and axial stiffnesses of the 'tension' wall pier were taken as $0.35 I_{g}$ and $0.75 \mathrm{Ag}$, respectively. The effective values for the 'compression' pier in the hinge region and for both piers above the expected hinge region were taken as $0.70 \mathrm{I}_{\mathrm{g}}$ and $1.00 \mathrm{~A}_{\mathrm{g}}$, respectively. Modeled stiffness values for both wall piers are given in Table 3. No reductions were applied to the stiffness of the steel coupling beams. The two-dimensional model is fully fixed at the base of each wall. All other nodes have all three degrees of freedom (horizontal and vertical translation and rotation) released. Consistent with the restraint provided by the floor diaphragms, the lateral 
degrees of freedom at each level of Wall 1 were constrained to those of Wall 2. Thus no axial forces will be developed in the coupling beams and there is no need to model the in-plane axial stiffness of the floor plates.

The degradation in stiffness of the CW components was incorporated using a simple bilinear hysteresis rule to model the steel coupling beams, and the Q-HYST degrading stiffness hysteresis rule to model the wall piers [29]. The steel coupling beam stiffness $\left(k_{0}\right)$ and yield strength $\left(\mathrm{F}_{\mathrm{y}}\right)$ parameters required for the bilinear hysteresis rule were obtained from the AISC Seismic Guidelines (2005)[31], and the post-yield stiffness factor, r, was assumed to be 0.02 [32].

The yield strength and post-yield stiffness factor for the two wall piers were obtained from nonlinear section analyses of the piers conducted using a commercially available non-linear fiber sectional analysis software package XTRACT [33]. Nonlinear models for both unconfined and confined concrete were used. The unconfined model was used for the concrete cover and wall webs that were reinforced with only minimum reinforcement requirements. The unconfined concrete strength was taken as $45 \mathrm{MPa}$. A confined concrete model, based on that of Mander et al. [34], was used for the boundary elements and barbells (minus their cover concrete) where significant transverse (confining) reinforcement was provided. The concrete stress-strain behavior was modified from the unconfined behavior based on the confining reinforcement ratio provided. A bilinear stress-strain relationship with $2 \%$ strain hardening was used to capture the nonlinear behavior of the 517 MPa reinforcing steel.

The predicted moment curvature behavior for each wall at each storey and for each analysis direction (48 M- $\varphi$ curves in all) was constructed using XTRACT. Individual curves were required since moment capacity is a function of axial load and this varies both over the height of the structure and with the direction of the applied pushover load. An example of the resulting $M-\varphi$ curves is shown in Figure 6. These curves were bilinearized to obtain the post yield stiffness factor, $\mathrm{r}$. The $\mathrm{r}$ values were averaged for each wall pier and used in subsequent RUAUMOKO analyses (Table 3). Because the study will progress to include time history analyses, it is necessary to model the wall piers in such a way that alternating tension and compression capacity may be captured. The six control points necessary to define the P-M interaction yield surfaces for the general quadratic beam elements were found from the complete axial load-moment (P-M) interaction yield surfaces calculated using XTRACT. 
Table 3 Modeling parameters for wall piers

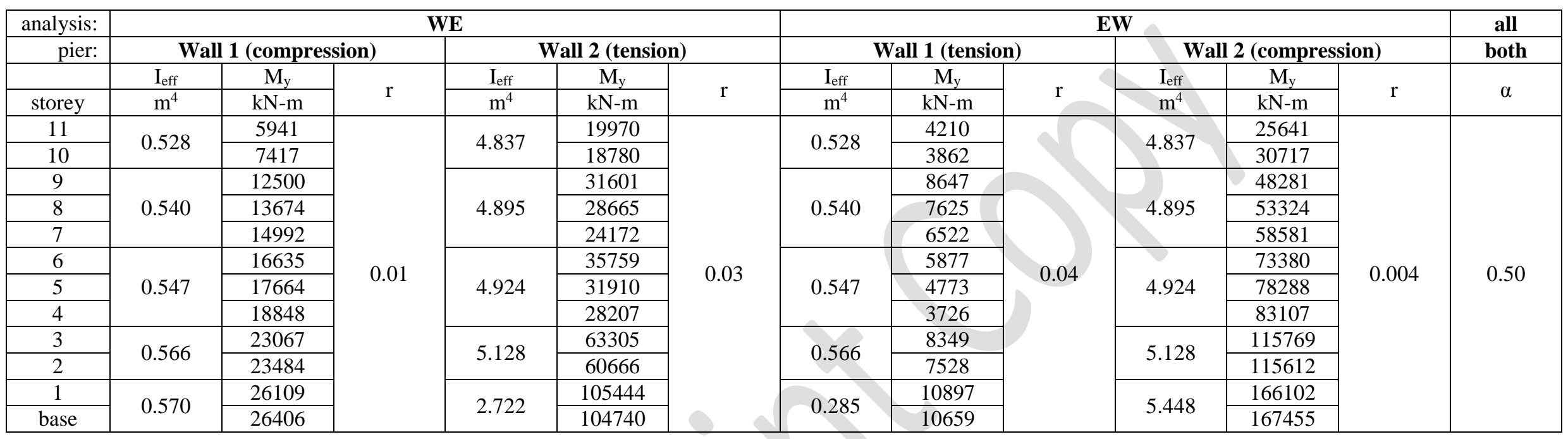

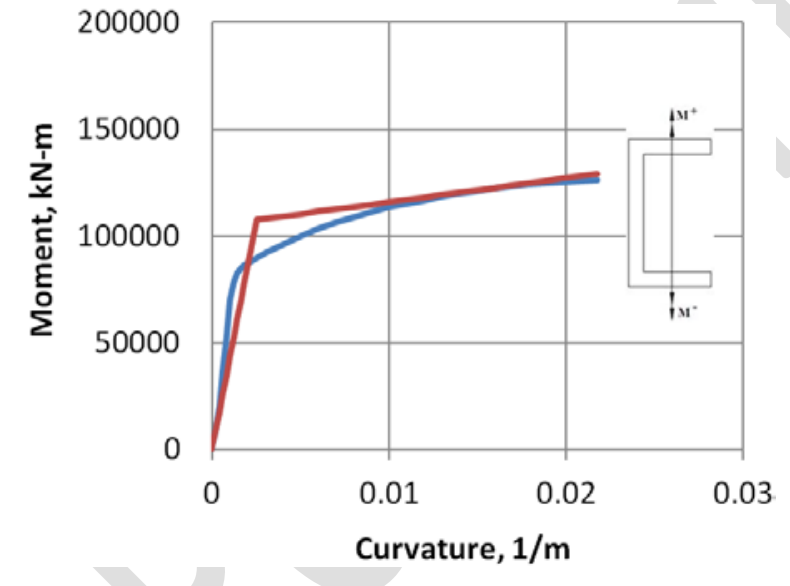

a) WE loading; Wall 2 is 'tension wall' (positive moments)

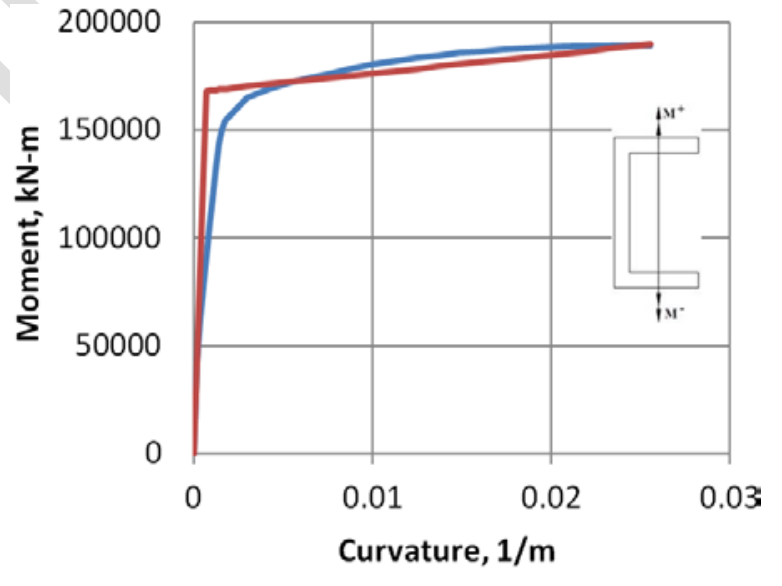

b) EW loading; Wall 2 is 'compression wall' (negative moments)

Figure 6 Example of calculated and bilinearized absolute moment-curvature relationships for the base of Wall 2. 
Although not necessary for a pushover analysis, conducting a modal analysis of a constructed model is good practice. The dynamic properties, in terms of modal periods (T) and the proportions of modal mass (mass participation factor, mpf) were determined. The first mode periods (2.28 s) are longer than the ASCE 7-10 [4] approximations (1.15 s) although this should be expected. The ASCE approximations are intended for use with typical cantilever wall structures and have been observed in the past to be poor indicators of CCW behavior. The effect of this shift is that the ELF procedure will overestimate the design base shear. Although refined methods of analysis (including modal procedures) are permitted by ASCE 7-10 [4], clause 12.9.4.1 limits the resulting reduced base shear to $85 \%$ of that calculated using the ELF method. Thus significant reductions are limited. The fundamental periods elongate as the coupling beams become more flexible (Table 4). This is expected since the flexible coupling beams (with the same wall piers) result in a more flexible structure. The period elongation is relatively small ( $2.28 \mathrm{~s}$ to $2.57 \mathrm{~s}$ ), indicating the dominance of the wall pier properties in the dynamic response of the structures. As indicated by the mass participation factors, the prototype structures are dominated by first mode behavior (expected for relatively uniform structures) and the first 3 modes are adequate to capture $90 \%$ of the structural response in all cases.

Table 4 First five natural vibration periods of the five prototype structures

\begin{tabular}{|c|c|c|c|c|c|c|c|c|c|c|}
\hline \multirow{2}{*}{ Mode } & \multicolumn{2}{|c|}{$\mathbf{1 0 0}$} & \multicolumn{2}{c|}{$\mathbf{9 0 \%}$} & \multicolumn{2}{c|}{$\mathbf{8 0 \%}$} & \multicolumn{2}{c|}{$\mathbf{7 0 \%}$} & \multicolumn{2}{c|}{$\mathbf{6 0 \%}$} \\
\cline { 2 - 11 } & $\mathrm{s}$ & $\mathrm{mpf}$ & $\mathrm{s}$ & $\mathrm{mpf}$ & $\mathrm{s}$ & $\mathrm{mpf}$ & $\mathrm{s}$ & $\mathrm{mpf}$ & $\mathrm{s}$ & $\mathrm{mpf}$ \\
\hline 1 & 2.28 & 70.79 & 2.33 & 70.67 & 2.40 & 70.71 & 2.49 & 70.41 & 2.57 & 70.17 \\
\hline 2 & 0.57 & 15.51 & 0.58 & 15.50 & 0.59 & 15.40 & 0.61 & 15.50 & 0.62 & 15.61 \\
\hline 3 & 0.25 & 5.65 & 0.25 & 5.72 & 0.25 & 5.73 & 0.25 & 5.85 & 0.26 & 5.93 \\
\hline 4 & 0.14 & 3.19 & 0.14 & 3.22 & 0.14 & 3.23 & 0.14 & 3.27 & 0.14 & 3.30 \\
\hline 5 & 0.09 & 1.91 & 0.09 & 1.93 & 0.09 & 1.95 & 0.09 & 1.97 & 0.09 & 1.98 \\
\hline
\end{tabular}

The purpose of conducting the pushover analysis in two directions is to investigate the variations in overall CCW system capacity, ultimate displacement, and sequence of hinge formation associated with the compression and tension stresses in both walls resulting from the coupling (frame) action. Prior to application of lateral loads, appropriate gravity loads tributary to the wall piers were applied. These loads were treated as forces and do not affect the seismic mass (i.e.: dynamic properties) of the structure. While the walls resist $100 \%$ of lateral loads, they carry only tributary gravity loads; therefore, the gravity loads tributary to the walls are 
significantly less than the seismic mass assigned to the walls. The presence of gravity loads is important as these resist uplift in the tension wall; their magnitude can be an important design parameter since typically designers prefer to avoid the situation of uplift. Once gravity loads are applied, the lateral pushover loads are applied incrementally.

The base shear versus roof displacement pushover curves for the WE and EW analyses are presented in Figures 7a and 7b, respectively. Four 'events' are identified on these curves: yield of the first and twelfth (last) coupling beam, yield of the first wall pier and, finally yield of the second pier, resulting in the formation of a mechanism representing the point of failure for the CCW system. A summary of predicted base shear and roof displacement at a) the ELF prescribed base shear, V = $7522 \mathrm{kN}$; b) first yield of a wall pier; and, c) the predicted ultimate capacity (formation of sufficient hinges to form a mechanism) are summarized in Table 5.

The EW pushover analyses resulted in higher ultimate strengths than the WE analysis. This is attributed to the higher resistance of the system resulting from the stiffer pier (Wall 2) being in compression. Added compression will generally increase the wall moment capacity while tension reduces the capacity. The dominance of Wall 2 in this analysis is apparent in the pushover results. For the purposes of design or evaluation, clearly the lower WE capacity would be adopted. The consideration of the weaker direction results in considerable overstrength and illustrates the potential degree of conservativeness inherent in CCW systems having significantly different pier geometries. The pushover analyses also validated the CCW designs and will serve as a basis of comparison with the nonlinear time history analyses.

Table 5 Base shear and roof displacement at different loading stages for the five structures

\begin{tabular}{|c|c|c|c|c|c|c|}
\hline \multirow[b]{2}{*}{ Structure } & \multicolumn{2}{|c|}{ Elastic } & \multicolumn{2}{|c|}{ at first yield of wall piers } & \multicolumn{2}{|c|}{ ultimate capacity } \\
\hline & $\begin{array}{l}\text { normalized } \\
\text { base shear }\end{array}$ & roof disp., mm & $\begin{array}{l}\text { normalized } \\
\text { base shear }\end{array}$ & roof disp., mm & $\begin{array}{l}\text { normalized } \\
\text { base shear }\end{array}$ & roof disp., mm \\
\hline & \multicolumn{6}{|c|}{ WE direction } \\
\hline $100 \%$ & \multirow{5}{*}{$\begin{array}{c}1.00 \\
(7522 \mathrm{kN})\end{array}$} & $194(\mathrm{H} / 223)$ & 1.13 & $226(\mathrm{H} / 191)$ & 1.39 & $389(\mathrm{H} / 111)$ \\
\hline $90 \%$ & & $208(\mathrm{H} / 208)$ & 1.13 & $252(\mathrm{H} / 171)$ & 1.36 & $405(\mathrm{H} / 107)$ \\
\hline $80 \%$ & & $231(\mathrm{H} / 187)$ & 1.11 & $271(\mathrm{H} / 159)$ & 1.34 & $434(\mathrm{H} / 100)$ \\
\hline $70 \%$ & & $276(\mathrm{H} / 157)$ & 1.06 & $298(\mathrm{H} / 145)$ & 1.28 & $476(\mathrm{H} / 91)$ \\
\hline $60 \%$ & & $307(\mathrm{H} / 141)$ & 1.02 & $316(\mathrm{H} / 137)$ & 1.25 & $506(\mathrm{H} / 85)$ \\
\hline \multicolumn{7}{|c|}{ EW direction } \\
\hline $100 \%$ & \multirow{5}{*}{$\begin{array}{c}1.00 \\
(7522 \mathrm{kN})\end{array}$} & $150(\mathrm{H} / 288)$ & 1.59 & $283(\mathrm{H} / 153)$ & 2.01 & $433(\mathrm{H} / 100)$ \\
\hline $90 \%$ & & $160(\mathrm{H} / 270)$ & 1.54 & $298(\mathrm{H} / 145)$ & 1.96 & $403(\mathrm{H} / 107)$ \\
\hline $80 \%$ & & $170(\mathrm{H} / 254)$ & 1.52 & $319(\mathrm{H} / 135)$ & 1.98 & $493(\mathrm{H} / 88)$ \\
\hline $70 \%$ & & $204(\mathrm{H} / 212)$ & 1.30 & $302(\mathrm{H} / 143)$ & 1.58 & $403(\mathrm{H} / 107)$ \\
\hline $60 \%$ & & $230(\mathrm{H} / 188)$ & 1.21 & $304(\mathrm{H} / 142)$ & 1.51 & $450(\mathrm{H} / 96)$ \\
\hline
\end{tabular}


In the WE analysis (wall 1 is in compression and wall 2 is in tension), the CCW systems of the five structures had good behavior in the elastic range which is generally below the ELF design criteria (base shear $=7522 \mathrm{kN}$ ). In the WE analysis, even the softest structure (60\%) exhibited relatively small roof displacement - on the order of $307 \mathrm{~mm}$ - at the code-prescribed base shear, and consequently satisfied the imposed 1\% roof drift limit (432 mm). These pushover analysis results appear to capture the limit of elastic behavior reasonably well indicating a relatively 'tight' CCW design with only marginal overstrength in the weaker WE direction, as intended, for this study (as opposed to having applied overstrength factors described by El-Tawil et al. 2009).

In Figures 7a and 7b, the initial slope of each curve represents the elastic behavior of the CCW system. In this range, the lateral force is resisted by the combined action of the coupling beams and wall piers in the manner assumed in design and in the elastic-based continuous medium method. Once beams begin to yield (open circle in Figure 7), the coupling action begins to degrade and the lateral forces once resisted by coupling frame action are redistributed to the wall piers. The sequence of coupling beam yielding, with the corresponding base shear (normalized to the ELF value $\mathrm{V}=7522 \mathrm{kN}$ ) and roof displacement, is shown in Figure 8 for the five prototype structures. As can be seen in this figure, the progression of coupling beam yield initiated near the one third height of the structure and progressed both upwards and downwards. Typically the roof beam remains elastic the longest since its demand is significantly reduced since no forces are applied above this point. In this analysis, the first floor beam yield was also delayed. This was a result of the restraining effect resulting from this beam being located so close to the fixed bases of the walls. A taller first storey (typical in many structures) will often lead the first floor beam to yield earlier in the analysis [22]. As the coupling beams yield, the properties of the CCW system change resulting in a) a decrease in the degree of coupling, doc; b) a decrease in structural stiffness resulting in c) an increase in the natural period of vibration; and d) an increase in the damping properties of the structure resulting from increased concrete damage. In subsequent nonlinear time-history analyses, all of these effects, with the exception of the change in damping, were captured.

In all five prototype structures analyzed in the WE direction, the initiation of the yield in the coupling beams started before the code base shear was achieved. In the $100 \%$ structure the process of the coupling beams yielding was complete beyond the elastic base shear, while for the 
90\% structure all beams had yielded at the code base shear. The coupling beam yielding for the $80 \%, 70 \%$ and $60 \%$ structures was completed before the code base shear was achieved. As the strength of the coupling beams was reduced from $100 \%$ to $60 \%$, the beams yielded earlier in the pushover analysis and forced the CCW system to evolve more rapidly to a system of two linked wall piers (LWP). From the capacity curves of the five structures, it is also found that even once the coupling beams had yielded and the structures functionally became sets of LWP's, the yield of wall piers at their base had not yet taken place; thus significant reserve stiffness and capacity remained.

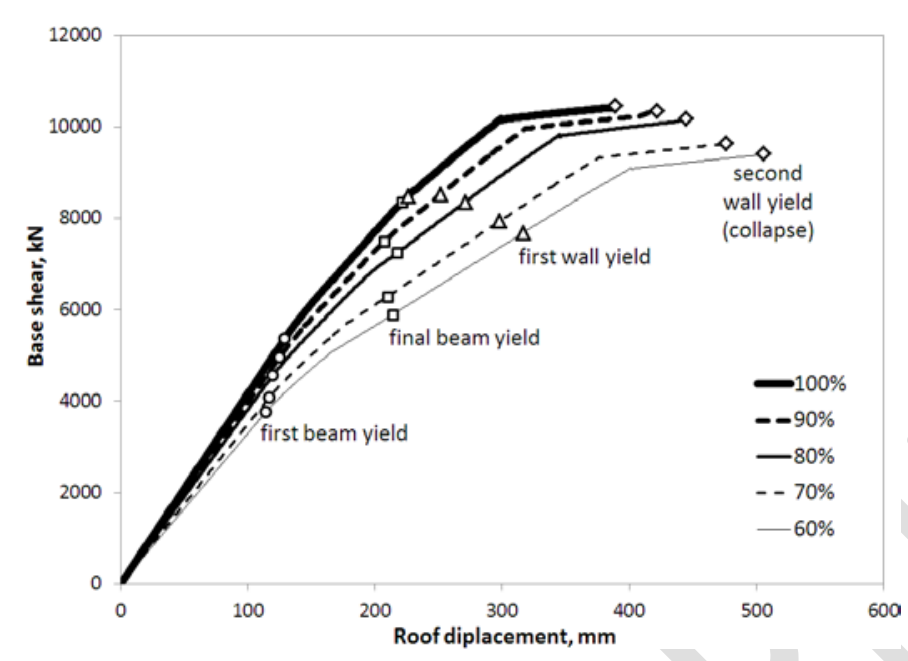

a) WE direction

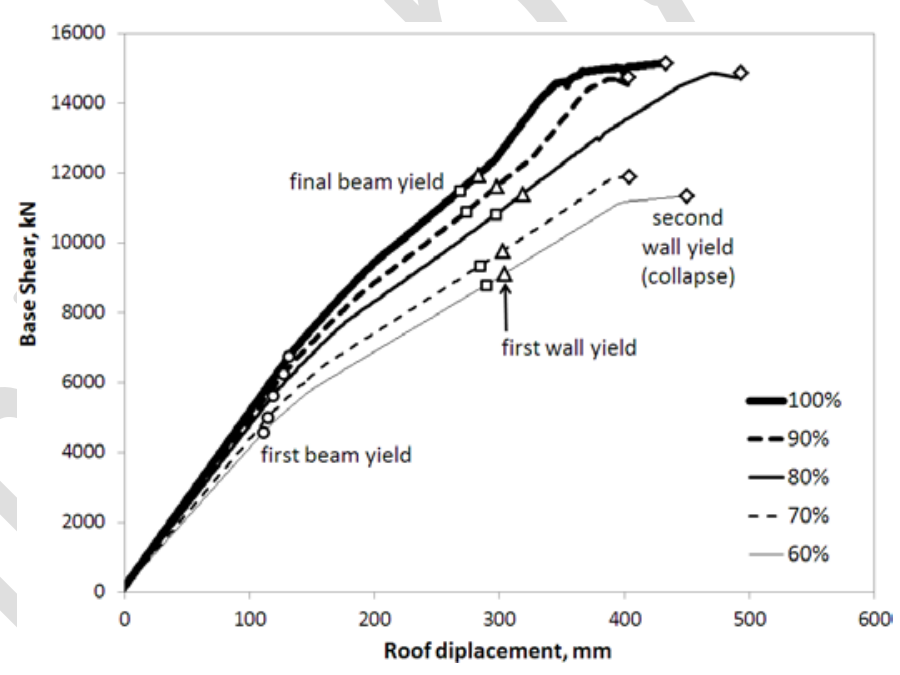

b) EW direction

Figure 7 Pushover curves.

Between the occurrence of first and final beam yield, the structure is transitioning from being a CCW to being a a collection of two linked wall piers (LWP). Once all coupling beams have yielded, but prior to yield of the first wall (Figure 7), the structure is no longer a CCW but a LWP. As the prototype coupling beams become more flexible (100\% to $60 \%$ structures), the beams yielded at a lower base shear. Nonetheless, the beam yield progression does not vary substantially as shown in Figure 8. As a result of the more flexible beams, the overall CCW capacity fell and the wall piers yielded at a lower base shear. Nonetheless, all capacities exceeded the ASCE 7 [4] design basis. Thus by leveraging the inherent overstrength of a CCW system and the ductility imparted as the system evolves from a CCW to a LWP, the coupling beams could safely be designed for only $60 \%$ of their demand and the structure would continue to perform adequately - this is the goal of a performance-based design. 
In the region between the beam yield and wall yield on the capacity curves, one can see the difference between a system of two cantilever walls designed to work separately and a system resulting from the evolution of a CCW system. The former system would have less capacity and stiffness, and hinge initiation would form immediately at the base of the walls when the system achieves the code base shear. Furthermore, it can be seen that the extent of this region increases as the strength of the coupling beams decreases (100\% to $60 \%)$. This observation suggests that the wall piers in this study are over-designed for the demands on the structure once again reflecting the inherent over strength prescribed by ASCE 7 [4].

Following yield initiation at the base of wall piers, the structures continued to show an increase in strength and roof displacement. Finally, the stiffness fell to essentially zero representing the formation of a complete mechanism (yield of all beams and both piers at their base). Figure 7 shows that as the coupling beams become more flexible $(100 \%-60 \%)$ the ultimate capacity of the system (base shear) decreases. Additionally, the ultimate roof displacement of the $100 \%, 90 \%$ and $80 \%$ satisfied the imposed roof drift limit of $1 \%$ (432 mm), although the roof displacement exceeded this limit in the $70 \%$ and $60 \%$ structures by 10 and $17 \%$, respectively. Nonetheless, all structures satisfied the typical code-prescribed limit of $2 \%$ (864 mm).

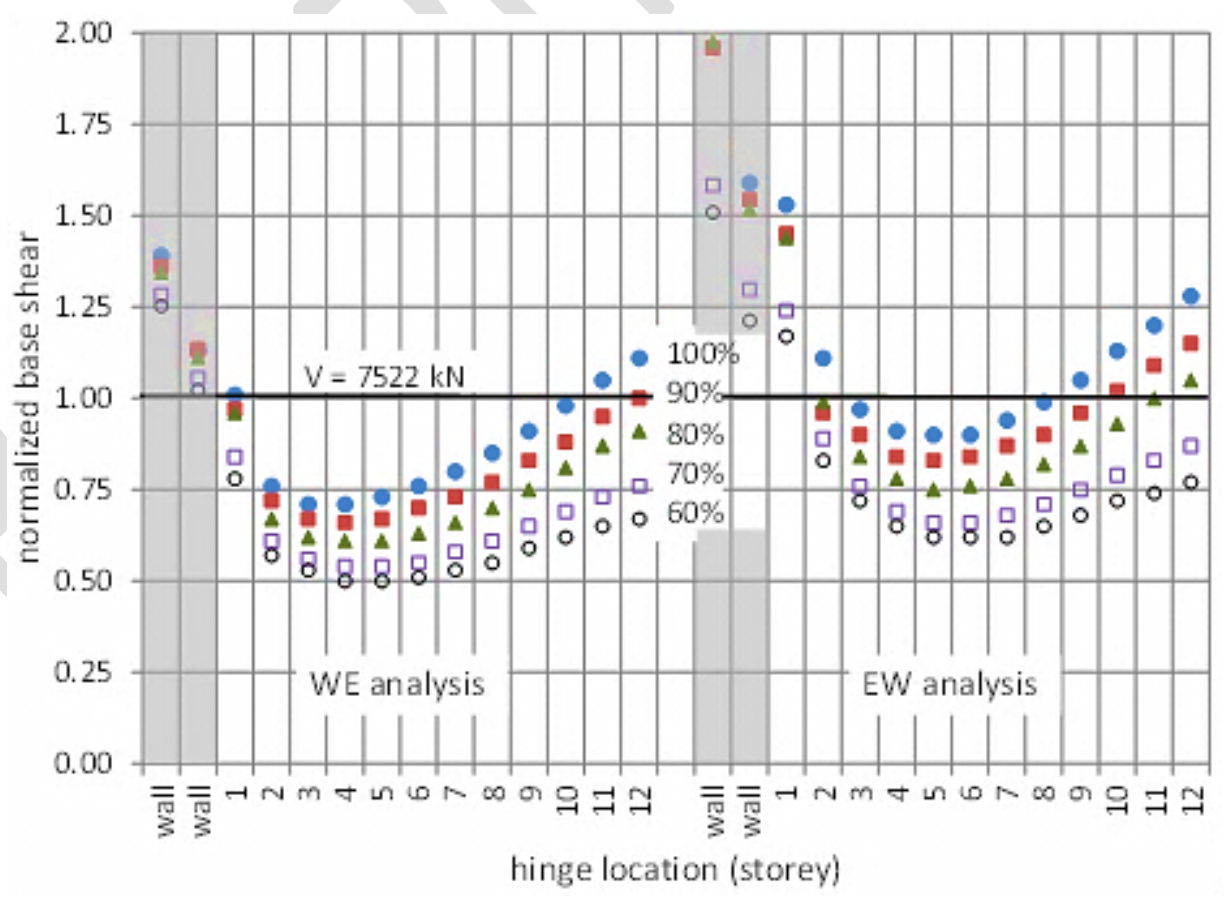

Figure 8 Progression of hinge formation in beams and walls. 
When conducting the pushover analysis in the EW direction (wall 1 is in tension and wall 2 is in compression), a different behavior was expected due to the large difference in wall pier geometry. In addition, there should be concern about the ability of the smaller wall 1 to handle the uplift axial force resulting from coupling action. For the prototype structure, uplift was not a great concern due partially to the large tributary gravity loads applied to the core walls. Additionally, as the coupling beams yield, the axial forces in the wall piers stabilize and may eventually diminish as the coupling beam strength begins to decay, although this was not modeled here since steel coupling beams having large ductility were used. Once the coupling beams yield, the frame action of the coupling beams is redistributed to the wall pier flexural action. Thus, permitting dual action or allowing 'weaker' coupling beams (60\% in lieu of $100 \%)$ may mitigate the potential for uplift in piers.

\section{NON-LINEAR TIME HISTORY ANALYSIS OF PROTOTYPE STRUCTURES}

The 2D model used for the pushover analysis was modified for the nonlinear dynamic analysis, where additional input parameters were required. Unlike the pushover analysis, during response history analysis, the two walls will sway back and forth resulting in each wall alternating between being the tension and compression wall piers (gravity loads are also applied, in which case the 'tension' wall may still have a net compressive force). Because the wall axial stress varies, the instantaneous flexural stiffness, moment capacity and post peak behavior also vary.

Using axial load-moment (P-M) interaction surfaces, the wall pier strength envelope at each storey was modeled accounting for the axial load at that level. It is impractical, however, to vary wall pier stiffness and post peak behavior. In these cases, both the effective moment of inertia of the pier, I, and the post-yield stiffness factor, r, were taken as the average of the values used in the pushover analysis as shown in Table 6. Similar to the pushover analysis, the bilinear and Q-HYST hysteresis rules were used to represent the inelastic behavior of the beam and wall pier members, respectively.

Table 6 Moments of inertia and post yield parameters of wall piers used for NLTHA

\begin{tabular}{|c|c|c|c|c|c|c|}
\hline \multirow{2}{*}{$\begin{array}{c}\text { Wall } \\
\text { section }\end{array}$} & \multirow{2}{*}{ Storey } & \multirow{2}{*}{ proportion of $\mathrm{I}_{\mathrm{g}}$} & \multicolumn{2}{|c|}{ Wall 1} & \multicolumn{2}{|c|}{ Wall 2} \\
\cline { 4 - 7 } & & $\mathrm{I}, \mathrm{m}^{4}$ & $\mathrm{r}$ & $\mathrm{I}, \mathrm{m}^{4}$ & $\mathrm{r}$ \\
\hline 1 & $1-2$ & $0.53 \mathrm{I}_{\mathrm{g}}$ & 0.428 & 0.025 & 4.086 & 0.017 \\
\hline 2 & $3-4$ & $0.70 \mathrm{I}_{\mathrm{g}}$ & 0.566 & 0.025 & 5.128 & 0.017 \\
\hline 3 & $5-7$ & $0.70 \mathrm{I}_{\mathrm{g}}$ & 0.547 & 0.025 & 4.924 & 0.017 \\
\hline 4 & $8-10$ & $0.70 \mathrm{I}_{\mathrm{g}}$ & 0.540 & 0.025 & 4.895 & 0.017 \\
\hline 5 & $11-12$ & $0.70 \mathrm{I}_{\mathrm{g}}$ & 0.528 & 0.025 & 4.837 & 0.017 \\
\hline
\end{tabular}


In this study, no site specific characteristics were assumed; thus ground motions were scaled to the ASCE 7 [4] design spectra determined for a 10\% probability of exceedance in 50 years (Figure 9), and each of the five prototype buildings was subjected to a suite of four ground motions. The motions ranged from moderate to severe records from past earthquakes. Each ground motion record was scaled such that its acceleration response spectral ordinate at $\mathrm{T}=2.28$ seconds - the first mode of the $100 \%$ prototype- was equal to that of the ASCE 7 design spectra. The scaled spectra are shown in Figure 9 and can be seen to generally exceed the ASCE 7 spectra for all higher modes $(\mathrm{T}<2.28 \mathrm{~s})$ [4].

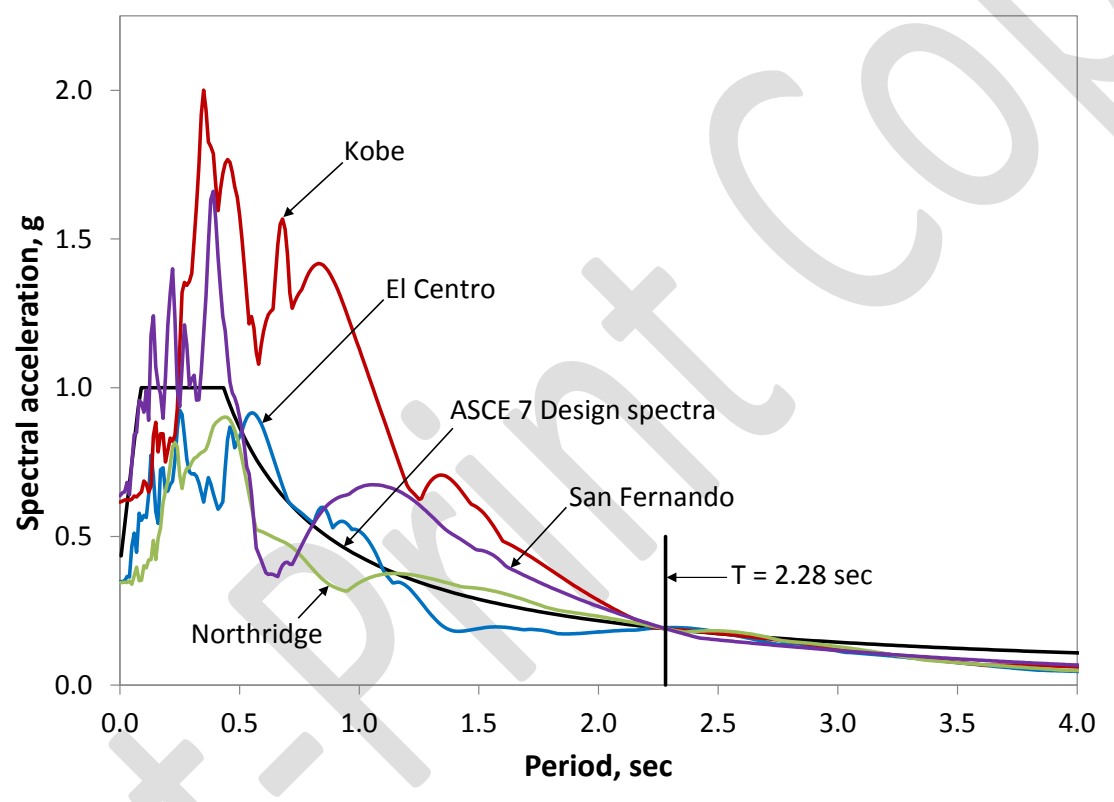

Figure 9 Response spectra for all ground motions.

Figure 10 shows the time history responses in terms of the roof displacement of the prototype structures during the suite of ground motions. During the suite of earthquakes, the maximum base shear demand for the five structures exceeded the code specified base shear $(\mathrm{V}=$ $7522 \mathrm{kN}$ ) estimated by the equivalent lateral force (ELF) procedure as shown in Table 7. From this table, the largest base shear for all structures occurred during the course of the Kobe excitation, while the smallest was observed for the Northridge event. The natural periods of the second and third modes for the five structures range from 0.57 to 0.62 seconds and 0.25 to 0.26 seconds, respectively (Table 4). Referring to Figure 9, it can be seen that the Kobe and El-Centro 
earthquakes have high spectral acceleration ordinates at the period of the second mode, while Northridge has the lowest.

Table 7 Maximum base shear forces and time of occurrence for the five structures

\begin{tabular}{|c|c|c|c|c|c|c|c|c|}
\hline \multirow{3}{*}{ Structure } & \multicolumn{8}{|c|}{ Earthquake } \\
\hline & \multicolumn{2}{|c|}{ El Centro } & \multicolumn{2}{|c|}{ Kobe } & \multicolumn{2}{|c|}{ Northridge } & \multicolumn{2}{|c|}{ San Fernando } \\
\hline & base shear & time & base shear & time & base shear & time & base shear & time \\
\hline- & $\mathrm{kN}$ & sec & $\mathrm{kN}$ & sec & $\mathrm{kN}$ & sec & $\mathrm{kN}$ & sec \\
\hline $100 \%$ & 20849 & 2.17 & 24318 & 5.6 & 12028 & 4.21 & 18011 & 3.52 \\
\hline $90 \%$ & 19203 & 2.17 & 25675 & 5.57 & 12246 & 4.43 & 15208 & 8.39 \\
\hline $80 \%$ & 18513 & 2.17 & 26454 & 5.6 & 11668 & 3.63 & 14577 & 2.79 \\
\hline $70 \%$ & 16828 & 2.18 & 26236 & 5.55 & 12099 & 3.62 & 15133 & 2.79 \\
\hline $60 \%$ & 17482 & 5.75 & 27245 & 7.93 & 12353 & 3.63 & 15195 & 2.79 \\
\hline
\end{tabular}

The seemingly anomalous behavior of the prototype structures subject to the San Fernando ground motion shown in Figure 10 results from large storey drifts in the upper storeys. The wall piers are not uniform along their height. The significant effects of higher modes or the combined effects of first plus higher modes are exciting the levels at which the wall piers transition from one detail (capacity) to another. In such a case, hinges were observed to form in the wall piers at these transitions (discontinuities) earlier in the time history. Once the coupling beams yield above this point, a mechanism forms resulting in very high interstorey and roof drifts [23]. The issue of interstorey drift in the upper three storeys could be addressed by extending the reinforcing detail of storeys 8-10 up to the roof level. This would provide more lateral stiffness and it won't affect the properties of the CCW system such as the doc at the base. In this case, extending the storey 8-10 reinforcing detail may prove an economical solution having little impact on the rest of the structure. This behavior highlights the complexity associated with the dynamic characteristics of non-uniform structures and structures having multiple lateral force resisting mechanisms such as coupled walls. 


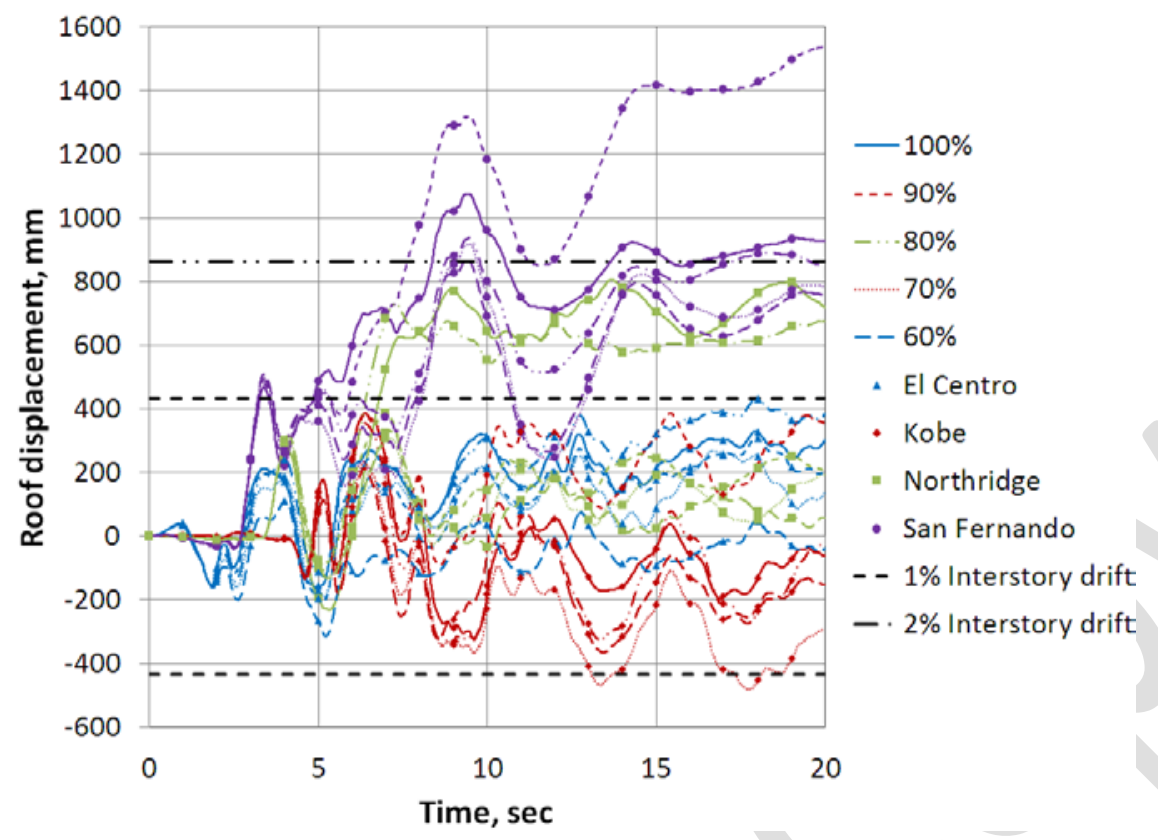

Figure 10 Roof displacement histories for all buildings for the suite of earthquakes considered.

The axial load-moment hysteresis responses at the base of the wall piers during the El Centro ground motion are shown in Figure 11. It can be seen that wall 2 response exceeded the P-M interaction surface indicating significant nonlinear behavior at the pier base. The nonlinear excursions occurred in the negative moment and positive axial load quadrant, indicating that the wall 2 was resisting the compression couple at the time of the excursion. 

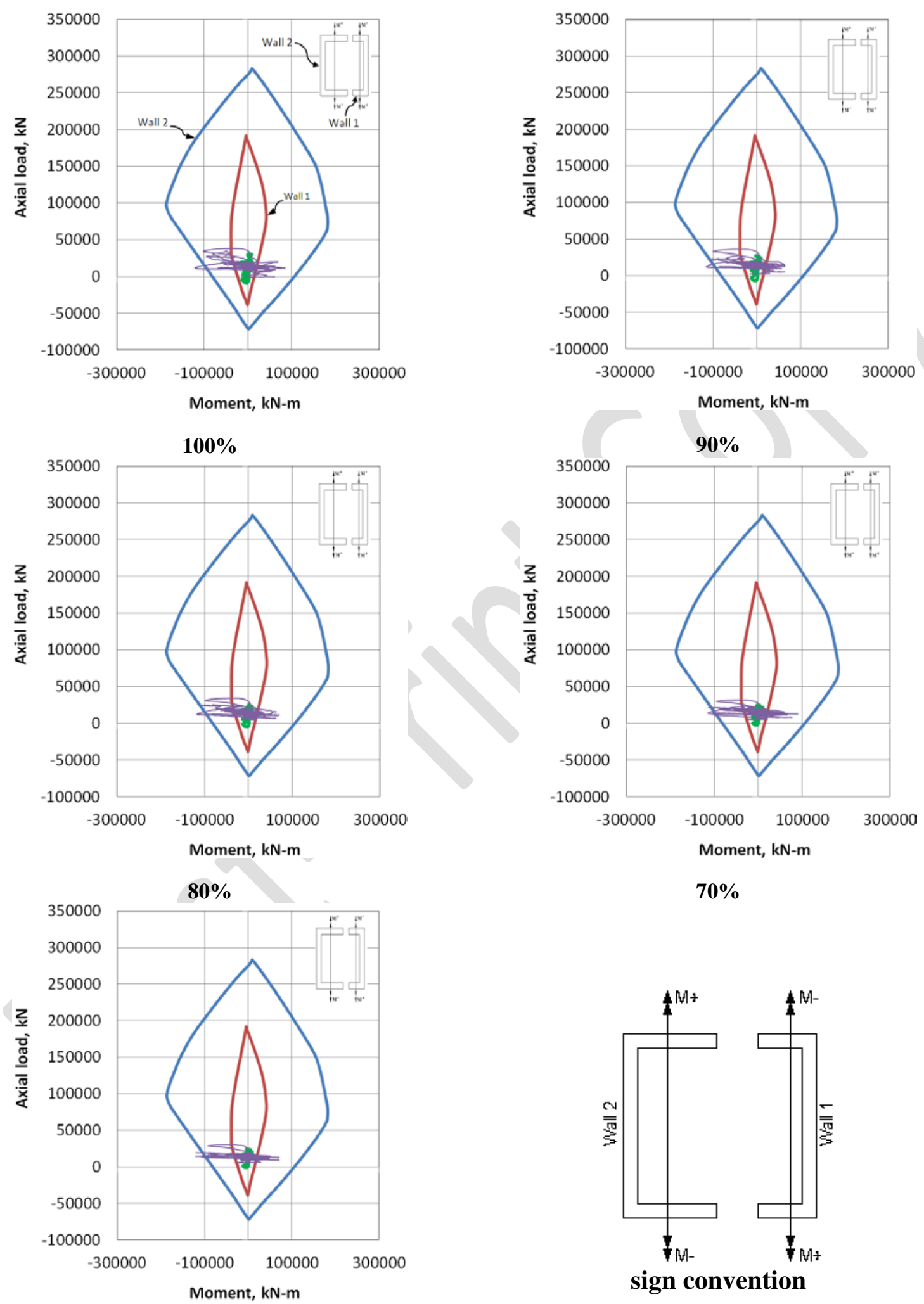

$60 \%$

Figure 11 Axial load-moment interaction at the base of the two walls for the El Centro ground motion. 
The higher demand in wall 2 for all analyses corresponds to peaks in base shear demands and indicates that the pier participated in dissipating the energy along with the coupling beams for these earthquake events. On the other hand, the smaller and flexible wall 1 remained elastic throughout most analyses. In the Kobe ground motion, both wall piers experience significant inelastic excursions at their bases. In this event, wall 2 yielded in tension and compression, while wall 1 yielded only in tension. The two piers showed no inelastic excursions at their base in the Northridge earthquake, indicating that both walls maintained their axial and flexural capacities. Similarly, the wall bases experienced only nominal inelastic deformation during the San Fernando earthquake where both walls yielded in tension; wall 2 multiple times while wall 1 yielded only once. As noted above, however, the behavior of the wall piers, especially for the San Fernando event, was dominated by behavior at higher stories rather than the pier bases. Finally, it should also be noted that the hysteretic properties used to define the wall piers in the analytical models are based on averaged parameters. This would underestimate the hysteretic characteristics of the compression wall and overestimate the hysteretic characteristics of the tension wall.

\section{CONCLUSION}

This study contributes to the state of the art of coupled wall (CW) analysis and design by introducing a new design paradigm: expanding the concept of performance-based design into a domain where the nature of the structural form evolves within the context of the proposed performance objective. It was shown that damage to the coupling beams in a CW system occurs prior to the plastic capacity of the system being achieved. Furthermore, the damage is progressive; resulting in a structural system that does, in fact, evolve from behaving as a coupled wall (CW) system to behaving as a collection of linked wall piers (LWP) as shown schematically in Figure 2. Based on this evolution of performance, the LWP system was found to be subject to large demands since the system is behaving as a stiffer CW system at lower performance levels. The work also investigated a procedure for proportioning the coupling beams that leads to acceptable structural behavior and failure mechanisms of the CW systems.

This study considered a prototype 12-storey reinforced concrete coupled core wall (CCW) building. Five CCW prototype structures, having varying degrees of coupling and the same wall piers were designed allowing the study of the effects of decayed coupling action to be carried out. Elastic analyses using the equivalent lateral force (ELF) procedure and the 
continuous medium method (CMM) were successfully used to establish initial proportions for the CCW system, and to determine the design forces and moments. Nonlinear static and dynamic analyses were conducted to investigate the CCW structural behavior, adequacy of the design, and the evolution of the structural form from CCW system to a collection of linked wall piers (LWP). A unique aspect of this work was that the wall piers in the CCW were significantly different in terms of their dynamic and geometric properties: the moments of inertia of the two wall piers differed by almost an order of magnitude.

From the behavior of the five prototype structures in this analysis, it is concluded that the dual systems, consisting of reinforced concrete wall piers and steel coupling beams, performed very well. The dual system provided superior lateral stiffness as a CCW in the elastic range, and maintained a good stiffness during the evolution toward a collection of linked wall piers (LWP). During the evolution process, the frame action degraded as the steel coupling beams yielded and formed hinges at their ends and the moment resistance was redistributed to the walls piers. Nonetheless, the prototype structures, even working as LWP, satisfied the imposed 1\% drift limit until the first yield of wall piers for both directions of analysis (WE \& EW).

At both the first yield of wall piers and the ultimate capacity stages, the coupling beams had essentially exhausted their capacities and experienced significant inelastic deformation demands, thus the CCW systems at these stages resist additional load only as a collection of linked wall piers (LWP).

The different wall pier capacities affected the performance although did not result in a significant reduction in capacity as may be initially intuited. The results of the EW pushover analysis showed that the ultimate capacities of the five structures exceeded their counterparts in the WE analysis. The higher capacities in the EW analyses resulted from the stiffer wall 2 being in compression and thus being even more dominant in the behavior of the system. In the WE analysis, when this wall was in tension, the overall system was more flexible since the dominant element was more flexible. Because the coupling beams in the WE pushover analysis yielded at a lower base shear than the EW analysis, the CCW evolved at lower applied lateral loads.

As expected, the structures having weaker coupling beams exhibited yield at lower lateral loads. The accompanying reduction in coupling stiffness and therefore degree of coupling (doc), however, mitigated this effect although the wall pier demand clearly rose with reduced coupling. 
In every case, however, the walls embodied sufficient overstrength to permit the overall structure to perform well.

The CCW system showed good energy dissipation capacity; even with the coupling beam capacity exhausted, the system still had a reserve capacity greater than the ELF design basis. Importantly, energy dissipation was distributed throughout the structure in both the coupling beams and wall piers making the CCW structure a very attractive option as lateral force resisting system (LFRS).

In the dynamic nonlinear analyses conducted, the structures exhibited similar behavior to that predicted in the pushover analyses. The dynamic analyses showed that, in general, all of the CCW systems behaved very well during the El Centro, Kobe and Northridge ground motions from the performance perspective of controlling roof drift.

Considering the performance criteria of limiting the roof drift, it is seen that reducing coupling beam capacity could be a key in developing constructible design (the need for this was developed by Harries et al. 2005) [3], as the analyses indicated little significant change to global structural performance from coupling beams designed for as low as $60 \%$ of their demand. Prototype structures with coupling beams strengths reduced to $80 \%$ satisfied a $1 \%$ drift limit, and all prototype structures satisfied a 2\% drift limit. Such 'weaker' beams are easier to design [3] and may result in a wider practical use of CW systems.

Furthermore, the consideration of five CCW structures that differ by $10 \%$ in their coupling beams stiffness may be seen as standing surrogate for the deterioration process of the $100 \%$ structure. So, if the $60 \%$ structure is considered as a 'step' in this deterioration process, the system at this stage is still showing acceptable behavior by satisfying a $2 \%$ drift limit and having an ultimate capacity exceeding the code design basis. The five analyses of differentstrength/stiffness coupling beams allowed the visualization of how the $100 \%$ structure would respond to different levels of lateral demand at different levels of deteriorated strengths and stiffness. 


\section{REFERENCES}

[1] Harries KA, Moulton D, Clemson R. Parametric study of coupled wall behavior implications for the design of coupling beams. ASCE Journal of Structural Engineering 2004a;130(3):480-488.

[2] American Concrete Institute, ACI 318-11, Building code requirements for reinforced concrete and commentary. Farmington Hills, Michigan; 2011.

[3] Harries KA, Fortney P, Shahrooz BM, Brienen P. Design of practical diagonally reinforced concrete coupling beams - A Critical Review of ACI 318 Requirements, ACI Structures Journal 2005;102(6):876-882.

[4] American Society of Civil Engineers, ASCE 7-10. Minimum design loads for buildings and other structures. Reston, VA; 2010.

[5] Harries KA. Ductility and deformability of coupling beams in reinforced concrete coupled walls. Earthquake Spectra 2001;17(3):457-478.

[6] El-Tawil S, Fortney P, Harries KA, Shahrooz BM, Kurama Y, Hassan M, Tong X. Recommendations for seismic design of hybrid coupled wall systems. ASCE/SEI; 2009. 80p.

[7] Paulay T, Santhakumar AR. Ductile behavior of coupled shear walls. ASCE Journal of the Structural Division 1976;102(ST1):93-108.

[8] Chitty L, Wan WJ. Tall building structures under wind load. $7^{\text {th }}$ International Conference on Applied Mechanics 1948;1(22):254-368.

[9] Beck H. Contribution to the analysis of coupled shear walls. American Concrete Institute Journal 1962;59:1055-1069.

[10] Coull A, Stafford-Smith B. Analysis of shear wall structures, symposium on tall buildings. Permagon Press, Oxford 1967:139-155.

[11] El-Tawil S, Kuenzli CM. Pushover of hybrid coupled walls. part ii: analysis and behavior. ASCE Journal of Structural Engineering 2002;128(10):1282-1289.

[12] Xuan G, Shahrooz BM, Harries KA, Rassati GA. A performance-based design approach for coupled core wall systems with diagonally reinforced concrete coupling Beams. Advances in Structural Engineering 2008;11(3):265-280.

[13] Santhakumar AR. Ductility of coupled shear walls. Ph.D. Dissertation, University of Canterbury NZ; 1974.

[14] Aristizabal-Ochoa JD, Sozen MA. Behavior of ten-storey reinforced concrete walls subject to earthquake motions. University of Illinois 1976;Report SRS No. 431.

[15] Lybas JM, Sozen MA. Effect of beam strength and stiffness on dynamic behavior of reinforced concrete coupled walls. University of Illinois 1977; Report SRS No. 444.

[16] Aristizabal-Ochoa JD, Shiu KN Corley WG. Effects of beam strength and stiffness on coupled wall behavior. Proceedings of the Second US National Conference on Earthquake Engineering 1979:323-332.

[17] Aktan AE, Bertero VV. Seismic response of $r / c$ frame-wall structures. ASCE Journal of the Structural Division. 1984;110(8):1803-1821. 
[18] Teshigawara M, Sugaya K, Kato M, Matsushima Y. Seismic test on 12-storey coupled shear wall with flange walls. Reprinted in list of technical papers written in English authored by japanside researchers, US-Japan Cooperative Earthquake Research Program on Composite and Hybrid Structures 1998.

[19] McNeice D. Performance-based design of a 30-storey coupled wall structure. MSCE Thesis. University of South Carolina; 2004.

[20] Hull D, Harries KA. On the application of fixed point theory to the design of coupled core walls. International Journal of Structural Stability and Dynamics 2008;8(1):161-186.

[21] Harries KA, Shahrooz BM, Brienen P, Fortney P. Performance based design of coupled walls. Proceedings of the $5^{\text {th }}$ International Conference on Composite Construction, South Africa 2004b.

[22] Harries KA, McNeice DS. Performance-based design of high-rise coupled wall systems. The Structural Design of Tall and Special Structures 2006;15(3):289-306.

[23] Eljadei A. Performance based design of coupled wall structures. Ph.D. Dissertation, University of Pittsburgh; 2012. 221p.

[24] Seto K, Ookuma M, Yamashita S, Nagamatsu A. Method of estimating equivalent mass of multi-degree-of-freedom system. JSME International Journal 1987;30(268):1638-1644.

[25] Stafford-Smith B, Coull A. Tall building structures - analysis and design. 1st ed. WileyInterscience; 1991. 537p.

[26] Harries KA, Mitchell D, Cook WD, Redwood RG. Seismic response of steel beams coupling reinforced concrete walls. ASCE Journal of the Structural Division. 1992;119(12):3611-3629.

[27] Harries KA, Mitchell D, Redwood RG, Cook WD. Seismic design of coupling beams - a case for mixed construction. Canadian Journal of Civil Engineering 1997;24(3):448-459.

[28] Harries KA, Shahrooz BM. Hybrid coupled wall systems. Concrete International. 2005;27(5):45-51.

[29] Carr AJ. RUAUMOKO - Inelastic dynamic analysis computer program. University of Canterbury 2008.

[30] Satyarno I, Carr AJ, Restrepo J. Refined pushover analysis for the assessment of older reinforced concrete buildings. Proc. NZ Nat. Soc. For Earthquake Engg, Tech Conf. Wairakei, 1998:75-82.

[31] American Institute of Steel Construction, ANSI/AISC 341-05. Seismic provisions for structural steel buildings, Chicago, Illinois; 2005.

[32] Gudimetla PS, Adibi-Asl R, Seshadri R. Incorporation of strain hardening effect into simplified limit analysis. Journal of Pressure Vessel Technology 2010;132(6):061201-06120110.

[33] Imbsen. XTRACT - cross sectional X structural analysis of components v3.0.9. Computer Program 2007.

[34] Mander JB, Preistley MJN, Park R. Theoretical stress-strain model for confined concrete. ASCE Journal of Structural Engineering 1988;114(8):1804-1826. 